\title{
,
}

NORK

\section{Vulnerable Boys: Short-term and Long-term Gender Differences in the Impacts of Adolescent Disadvantage}

\author{
Ziteng Lei \\ Shelly Lundberg
}

Working Paper

2020-008

$01 / 2020$

The University of Chicago

1126 E. 59th Street Box 107

Chicago IL 60637 


\title{
Vulnerable Boys: Short-term and Long-term Gender Differences in the Impacts of Adolescent Disadvantage
}

\author{
Ziteng Lei Shelly Lundberg* \\ University of California, Santa Barbara
}

January 28, 2020

\begin{abstract}
The growing gender gap in educational attainment between men and women has raised concerns that the skill development of boys may be more sensitive to family disadvantage than that of girls. Using the National Longitudinal Study of Adolescent to Adult Health (Add Health) data we find, as do previous studies, that boys are more likely to experience increased problems in school relative to girls, including suspensions and reduced educational aspirations, when they are in poor quality schools, less-educated neighborhoods, and father-absent households. Following these cohorts into young adulthood, however, we find no evidence that adolescent disadvantage has stronger negative impacts on long-run economic outcomes such as college graduation, employment, or income for men, relative to women. We do find that father absence is more strongly associated with men's marriage and childbearing and weak support for greater male vulnerability to disadvantage in rates of high school graduation. An investigation of adult outcomes for another recent cohort from the National Longitudinal Survey of Youth, 1997 produces a similar pattern of results. We conclude that focusing on gender differences in behavior in school may not lead to valid inferences about the effects of disadvantage on adult skills.
\end{abstract}

Keywords: Gender, education, employment, earnings, family structure, father absence, school quality, neighborhood effect

JEL Classification: J24, J12, J16

*Ziteng Lei is a PhD student at the University of California, Santa Barbara and can be reached at ziteng_lei@umail.ucsb.edu. Shelly Lundberg is the Leonard Broom Professor of Demography at the University of California, Santa Barbara and a Research Fellow, Institute for the Study of Labor (IZA) (slundberg@ucsb.edu). This paper draws on earlier work in Lundberg (2017) and she is grateful for comments on that paper from participants in a Workshop on Early Care Interventions and Their Effects on Children and Families at Aarhus University, a Workshop on Family Economics at Copenhagen University, the 1st Annual IZA Workshop on Gender and Family Economics, the Population Association of America Annual Meetings in Washington D.C., the annual conference of the European Society for Population Economics in Berlin, and seminars at Texas A\&M, Duke University, Boston University, Melbourne Institute, Monash University, Macquarie University, and the University of Technology Sydney. 


\section{Introduction}

In 1990, the proportion of young women (aged 25 to 29) who had completed four-year college degrees reached near equality with young men in the United States after steadily increasing for several decades. By 2014, the long-standing gender gap in educational attainment had not just disappeared but reversed - favoring women by a substantial margin. More than 37 percent of young women now have at least a four-year college degree, compared to less than 31 percent of young men (U. S. Census, 2016b). Similar gender gaps in education are opening up around the world, with young women completing tertiary degrees at higher rates than men in almost all OECD countries (OECD, 2015).

Rising female educational attainment has been a consequence of the removal of barriers to women's schooling and market work that had discouraged investments in women's human capital. However, the emergence of a female advantage in higher education rather than parity, even though women continue to have lower employment rates and shorter work hours than men, has been unexpected. Some studies find a gender gap in benefits to education, such as a higher college wage premium for women than for men (Dougherty, 2005) but a consensus seems to be emerging that the principal source of the college gap lies in gender differences in the non-pecuniary costs of educational persistence. These cost differences are reflected in a persistent male disadvantage in school performance at all levels and are due, some argue, to lower levels of non-cognitive skills among boys and the resulting "behavioral advantage" of girls (Fahle and Reardon, 2018).

An extensive literature in education and the social sciences has documented gender differences in the academic and behavioral outcomes of boys and girls in elementary and secondary school (Buchmann, DiPrete, and McDaniel, 2008; DiPrete and Buchmann, 2013; Salisbury, Rees, and Gorard, 1999). These gender gaps are not new phenomena: girls have consistently outperformed boys in grades and have been less likely to get in trouble at school (Duckworth and Seligman, 2006). Recent studies interpret the observed gender differences in academic performance, grade repetition, special education placement, homework hours and school reports of disruptive behavior as indicative of gaps between the non-cognitive skills of boys and girls (Becker, Hubbard, and Murphy, 2010; Goldin, Katz, and Kuziemko, 2006; Jacob (2002)). Gender gaps in social and behavioral skills appear to develop early - girls begin school with more advanced learning and social skills than boys, and this advantage grows over time. These early skill gaps, in turn, explain much of the gender differential in later academic achievement and educational attainment (DiPrete and Jennings, 2012; Owens (2016)).

Economists have focused on possible causes of this gender gap in behavior, including the possibility that the development of capabilities that enhance academic achievement, such as self-control, is more sensitive to family disadvantage among boys than is the skill development of girls. Autor and Wasserman (2013) suggest that the increased prevalence of single-parent families and decreased contact with a stable male parent may have a particularly negative impact on boys and contribute to the growing gender gap in educa- 
tion and to male labor market difficulties, either because boys are more vulnerable to the loss of parental time and financial resources, or due to role model effects of the same-sex parent. ${ }^{1}$ Two recent studies report empirical evidence consistent with this hypothesis. Bertrand and Pan (2013) find that the gender gap in early behavior problems and school suspensions is much larger for the sons and daughters of single mothers than for children in two-parent households. They interpret this as evidence that the non-cognitive skills of boys are adversely impacted by non-traditional family arrangements, and suggest that boys' greater tendency to act out and develop conduct problems might be particularly relevant to their relative absence in college. Autor, Figlio, Karbownik, Roth, and Wasserman (2019) examine the effects of several dimensions of family disadvantage, including mother's education and marital status, an SES index, neighborhood income and school quality on school performance, behavior, and on-time high school graduation for a large sample of children in Florida. They find that indicators of family disadvantage tend to have significantly greater effects on schooling outcomes for boys, compared to girls.

In this study,we move beyond K-12 achievement and behavior to assess the role of excess male vulnerability to adverse childhood environments in explaining gender gaps in college graduation and other adult outcomes. This requires data that permits us to link family structure and characteristics of schools and neighborhoods in childhood with longer-term outcomes, including final educational attainment, and we use rich longitudinal data from the National Longitudinal Study of Adolescent to Adult Health (Add Health). In particular, we examine the association between family disadvantage in adolescence and outcomes that include behavior in school, mental health and educational aspirations in adolescence, and educational attainment, employment, income, marriage and fertility in young adulthood, for a recent cohort of young adults.

We find, as do previous studies, that boys are more sensitive than girls to father absence in terms of problems with schoolwork and interactions in school. Girls, however, are more likely than boys to respond to father absence with increased levels of depression, and are particularly negatively affected by residence with a stepfather. When we turn to educational attainment and other adult economic outcomes in later waves of Add Health, we find that family structure in adolescence does not have differential effects on the college graduation rates, income, and job stability of men and women. Family structure in adolescence does differentially affect men and women in terms of family decisions in

\footnotetext{
${ }^{1} \mathrm{~A}$ few studies have found that boys do worse, emotionally and academically, following a divorce (Hetherington and Kelly, 2002), but meta-analysis of (correlational) studies of father absence and child wellbeing by Amato and Gilbreth (1999) finds no support for the hypothesis that boys benefit more than girls from paternal involvement. Prevoo and ter Weel (2015) examine the impact of family disruption on children's personality development and find that behavior problems and self-esteem among teenage boys are more responsive to parental death, but not family disruption in general, compared to girls. The vulnerable male story is also difficult to square with the findings of Bailey and Dynarski (2011) that the growing gender gap in college attendance rates is driven primarily by increases in the education of daughters of high-income parents.
} 
young adulthood, including marriage and fertility. Results using data of another recent cohort of young adults from the National Longitudinal Survey of Youth, 1997 produce a similar pattern of results. In addition we find, as do Autor et al. (2019), that the behavior of adolescent boys is more responsive to other indicators of disadvantage, such as poor quality schools and less-educated neighborhood, than is the behavior of girls. These differential environmental effects, however, also fail to persist into adulthood.

A few other studies have focused on gender differences in the adult impacts of early life disadvantage. Closest to our design is Brenøe and Lundberg (2018), who are able to assess some long-term effects of family disadvantage with Danish administrative data. Linking entire population cohorts from birth into adulthood, they find that family disadvantage, particularly low maternal education, has more negative effects on school-age outcomes of boys relative to girls, as expected. Administrative data provides few adolescent measures; the key outcome is a marker for completing primary school on time. Long-term effects are quite different: early disadvantage, particularly low parental education, tends to have stronger impacts on the educational attainment, employment, and earnings of adult women, compared to adult men. ${ }^{2}$ Autor et al. (2019) find that mother's marital status and education have larger effects on son's high school graduation than daughter's, but are not able to follow subjects further. Fan, Fang, and Markussen (2015) use Norwegian administrative data to show that mother's employment early in a child's life is more negatively associated with the educational attainment of sons than daughters, suggesting that they are more adversely affected by a reduction in maternal time. Finally, Gould, Lavy, and Paserman (2011) present contrary results in a different environment-Yemenite child refugees in Israel who were placed in more modern environments achieved higher education and employment rates, but these benefits accrued largely to women.

Our results, which show that short-run differential impacts of disadvantage on boys and girls are not reflected in long-term outcomes, suggest that it may be premature to interpret the greater responsiveness of boys' behavioral and school disciplinary problems to father absence and other dimensions of adolescence disadvantage as evidence of a gender gap in non-cognitive skills. School-age boys and girls appear to respond to adolescent environments and resources with distinct, gender-typical behaviors that haven't been previously noted in this context, rather than developing a skill gap with implications for adult economic outcomes, such as the gender gap in college graduation. Though nontraditional family structures and adverse environments in adolescence are associated with lower educational attainment and poor labor market outcomes for both men and women, there appears to be no significant gender difference in the effects on college graduation rates and labor market outcomes. Disadvantage in adolescence does have some distinct effects on marriage and fertility for men and women, but we find little evidence supporting

\footnotetext{
${ }^{2}$ Family structure and parents' marital status at birth tend to have weak and inconsistent effects on later outcomes, but there is less variation in these indicators than in U.S. data and the comprehensive Danish social welfare system may mitigate the impacts of family disruption on children.
} 
a general pattern of excess male vulnerability.

\section{Data}

\subsection{Add Health Sample}

The National Longitudinal Study of Adolescent to Adult Health (Add Health) has collected a rich array of longitudinal data on the social, economic, psychological and physical well-being of young men and women in the U.S. from adolescence through young adulthood. ${ }^{3}$ The Add Health study began in 1994-95 with a nationally-representative school-based survey of more than 90,000 students in grades 7 through 12 . The students were born between 1976 and 1984 and attended one of 132 schools in the sampling frame. About 20,000 respondents were followed in subsequent surveys; the last completed survey (Wave IV) was conducted in 2007-08 when the respondents were between 24 and 32 years of age.

Most of our analysis is based on a subsample of white, non-Hispanic men and women. Father-absent households are much more prevalent in the Black and Hispanic Add Health samples, and school and neighborhood characteristics are also very different on average. Because our focus is on gender differences in the impact of adolescent environments, and these may differ between, for example, households with foreign-born vs. native-born parents or schools with disciplinary regimes of varying harshness, we have chosen to focus on a more homogenous core sample. Key results for the Black subsample are presented in section 4.5; the Hispanic subsample is too small to support a separate analysis.

Table A1 illustrates the selection of our Add Health analysis sample: the columns present mean values for the full Add Health Wave I sample, the full sample with complete data on key variables, the white, non-Hispanic sample, this sample with only those living with biological mother at Wave I and with non-missing maternal characteristics, and finally the sample remaining in the survey at Wave IV. This, the final analysis sample, contains 3,868 non-Hispanic white women and 3,459 non-Hispanic white men. With the exception of the race/ethnic subsampling, these sample restrictions have very little impact on the demographics of the sample. ${ }^{4}$ The descriptive statistics by gender for this sample

\footnotetext{
${ }^{3}$ This research uses data from Add Health, a program project directed by Kathleen Mullan Harris and designed by J. Richard Udry, Peter S. Bearman, and Kathleen Mullan Harris at the University of North Carolina at Chapel Hill, and funded by grant P01-HD31921 from the Eunice Kennedy Shriver National Institute of Child Health and Human Development, with cooperative funding from 23 other federal agencies and foundations. Special acknowledgment is due Ronald R. Rindfuss and Barbara Entwisle for assistance in the original design. Information on how to obtain the Add Health data files is available on the Add Health website (http://www.cpc.unc.edu/addhealth). No direct support was received from grant P01-HD31921 for this analysis.

${ }^{4}$ The discrepancy in the male-female sample sizes is the result of consistently lower rates of both contact and response for male Add Health sample members. Attrition from the panel is higher for men than for women: in section 3 we show that this differential attrition is independent of family structure and
} 
are summarized in Table A2.

\subsubsection{Adolescent Outcomes}

The Add Health Wave I survey collected an array of student-reported variables, including experiences in school, health, personality, and relationships with parents, siblings, friends and others. Most respondents were between the ages of 12 and 17 . We use self-reports of Math and English grades and of school problems, including school suspensions, to generate academic and behavioral outcomes that are similar to those in previous studies and augment this with a standard depression scale and reports of educational aspirations.

- School Problems: Students were asked about problems they experience in school, including trouble getting along with teachers and other students, trouble getting homework done and trouble paying attention in class (coded 0-4 from never to every day), how many times they have been absent without an excuse, and whether they have ever received an out-of-school suspension. Factor analysis was used to aggregate these measures into a standardized school problems index. Misbehavior in school, including absenteeism, inattention, and suspensions, are strongly predictive of adult labor market outcomes and criminal behavior (Segal, 2013; Lundberg, 2017b) and school suspensions are a key outcome in both Bertrand and Pan (2013) and Autor et al. (2019). In our sample, the proportion of boys who report ever having been suspended is more than twice that of girls, and their level of school problems is 0.3 standard deviations higher (Table A2).

- Depression: Wave I respondents were asked how often during the past week they felt sad, lonely, depressed, blue, happy, or hopeful. These six items (plus 13 more) are the components of CES-D, a standard depression scale (Radloff, 1977). Factor analysis indicated that a single factor is appropriate for these 19 items and was used to form a standardized depression index. Table A2 shows that reported depression among adolescent girls is much higher than among boys.

- Grades and Aspirations: As a measure of academic achievement, we use student reports of their math and English grades in the most recent grading period. Girls' mean English grade is 0.375 grade points higher than boys', but their math grades are only slightly higher on average (Table A2). Educational aspirations in Wave I are based on student responses (on a 5-point scale) as to how much they want to attend college, and how likely they think it is that they will attend college. Add Health respondents are very optimistic about their college prospects on average, but girls are substantially more likely to report that they both want and expect to attend. Fortin, Oreopoulos, and Phipps (2015) find that much of the gender gap in high school achievement can be attributed to the gender difference in educational expectations,

examine other gender selection issues. 
particularly those linked to career plans that include a graduate degree. Add Health students were also asked about how likely they are to be married at age 25 , on a 5 -point scale.

\subsubsection{Adult Outcomes}

Our principal goal is to examine whether deficits in early skills and aspirations due to family disadvantage have long-term implications for gender gaps in economic and social outcomes in adulthood. The Wave IV survey collected an array of adult outcomes, including educational attainment, employment and income, and family histories.

- Educational Attainment: Highest educational attainment is collected when most respondents are between 25 and 31 years of age. Most, though not all, will have completed their final level of formal schooling at this point. We focus on the attainment of a 4-year college degree, since the rising returns to education in recent decades have largely been restricted to college graduates. Though there is a gender gap in high school graduation and college attendance as well, the college graduation gap has received the most attention given its substantial implications for lifetime income. However, we also examine high school graduation, imputed years of schooling, and a categorical education variable that ranges from $0=$ less than high school to $5=$ post-graduate degree. As expected, we see a moderate gender gap in high school graduation rates and a substantial one in college graduation in our analysis sample (Table A2).

- Employment and Income: Deficits in non-cognitive skills and limited schooling are likely to lead to adverse labor market outcomes. We examine self-reported beforetax personal earnings, and define respondents as currently employed if they report working for pay at least 10 hours a week. We also consider two other aspects of employment histories: number of times fired ${ }^{5}$ and satisfaction with current or last job $^{6}$, as these may reflect non-cognitive skills. A dummy variable for financial stress is based on respondent reports that they have faced difficulties in paying bills in the past year. ${ }^{7}$ This measure is likely to be driven both by economic resources and by skills associated with managing those resources. Male respondents are, as expected,

\footnotetext{
${ }^{5}$ The survey question asks, "Thinking back over the period from 2001 to the previous year, how many times have you been fired, let go or laid off from a job?"

${ }^{6}$ The survey question asks "How satisfied (are/were) you with this job, as a whole?" on a 5 point scale.

${ }^{7}$ The financial stress dummy is set equal to one if there is a positive response to at least one of: "without phone service because you didn't have enough money", "didn't pay the full amount of the rent or mortgage because you didn't have enough money", "were evicted from your house or apartment for not paying the rent or mortgage", "didn't pay the full amount of a gas, electricity, or oil bill because you didn't have enough money", "had the service turned off by the gas or electric company, or the oil company wouldn't deliver, because payments were not made", and "worried whether food would run out before you would get money to buy more".
} 
more likely to be employed than women, and also report higher earnings and lower levels of financial stress. Men are more likely to report being fired than women and have roughly equivalent levels of job satisfaction.

- Marriage and Children Ever Born: Marriage and fertility histories are collected in the Wave IV survey. Half of the Add Health respondents have never been married at the time of Wave IV survey; we focus on a dummy variable for ever married as our key outcome. The respondents were also asked about the number of times they have been pregnant/have made a partner pregnant, and the live births resulting from these pregnancies. Add Health men are less likely to have been married and report fewer children than women, reflecting the expected gender differences in the timing of family formation.

- Depression: The Wave IV survey includes a shorter (11 item) version of the depression instrument in Wave I, and we include this in the analysis to see how persistent family and environmental influences on this mental health indicator are. ${ }^{8}$

\subsubsection{Indicators of Disadvantage in Adolescence}

- Father Absence in Wave I: A large literature has documented the empirical relationship between single parenthood, family instability, and a child's prospects for success in adulthood (McLanahan and Sandefur, 1994; Lopoo and DeLeire, 2014; Woessmann, 2015), though causal inference has been difficult given the confounding effects of unobserved parental, child, and environmental characteristics. The restricted economic and parental resources in single-parent families are very likely, however, to limit investments in children and adolescents. Though nearly 90 percent of the Add Health respondents were living with their biological mother in Wave I, almost 10 percent were also living with a step-father or other father figure rather than their biological or adoptive father, and nearly 22 percent were living with no father figure at all. Girls were 15 percent more likely to be living with no father in the household than were Add Health boys.

- School Quality: Autor et al. (2019) find that poor quality schools have a particularly disadvantageous effect on school outcomes for boys and that this environmental influence is distinct from the effects of family disadvantage. The Add Health Study includes a school administrator questionnaire that can be used to construct a standardized index of school quality for the schools attended in Wave I. The components of the index are average daily attendance, class size, percentages of new and of experienced teachers, the share of teachers with a Masters degree, grade 12 dropout rates, percentages of students with standardized achievement tests at, below, or

\footnotetext{
${ }^{8}$ Factor analysis indicated that a single factor is appropriate for these 11 items and was used to form a standardized depression index.
} 
above grade level, and the share of 12 th graders who enrolled in a 2-year or 4-year college the next year.

- Neighborhood: A growing literature finds that neighborhood characteristics appear to have long-term causal impacts on economic outcomes for children, and that boys may be differentially sensitive to these forces (Chetty et al., 2016; Chetty and Hendren, 2018; Autor et al., 2019). The Add Health Contextual Database provides an array of community characteristics that enable researchers to investigate contextual influences for a wide range of adolescent behaviors. ${ }^{9}$ We use an indicator for "educated neighborhood" defined as the proportion of individuals aged $25+$ with a college degree or more at the census tract level.

\subsubsection{Maternal Characteristics}

Maternal characteristics are included as control variables in most regressions. The educational attainment of the respondent's biological mother is divided into 4 categories, "less than high school", "high school degree", "some college", and "college degree or more". We also included indicators for whether the biological mother is foreign-born and young (under age 22) at the birth.

\section{$2.2 \quad$ NLSY97 Sample}

We examine the robustness of our analysis of Add Health with the National Longitudinal Survey of Youth 1997 (NLSY97), which provides comparable measures of adult (but not comparable adolescent) outcomes for a set of birth cohorts similar to Add Health. NLSY97 is a representative longitudinal study with surveys from 1997 (round 1) to 20152016 (round 17). The cohort was born between 1980 and 1984, with respondents aged between 12 and 18 at the time of the first interview and between 30 and 36 at round 17 . As in our Add Health models, we analyze a subsample of non-Hispanic white women and men. Details regarding the sample, variable construction, and a comparison with the Add Health sample are in the Data Appendix.

\section{Empirical Strategy}

Obtaining a causal estimate of the difference in the impacts of father absence and other indicators of family disadvantage on outcomes for boys and girls requires that the distribution of male and female children across households with and without fathers be identical in terms of their potential outcomes with a father present. For any outcome $Y$ for boys

\footnotetext{
${ }^{9}$ For most respondents participating in the Add Health in-home survey, Wave I home locations were identified. When possible, these residence locations have been geocoded in order to link them to contextual data that is available from many other sources.
} 
(b) and girls $(g)$, we can define possible outcomes in alternative family structures as:

$$
\begin{aligned}
& Y_{b}=(1-D) Y_{b}(0)+D Y_{b}(1) \\
& Y_{g}=(1-D) Y_{g}(0)+D Y_{g}(1)
\end{aligned}
$$

where $Y_{i}(0)$ is the potential outcome of child $i$ if his or her father is present in the household $(D=0)$, and $Y_{i}(1)$ is the potential outcome if his or her father is absent $(D=1) . Y_{i}$ is the observed outcome.

In general, the causal impact of father absence cannot be determined by comparing outcomes for children in different types of household due to the confounding effects of unobserved parental, child, and environmental influences. The average difference in outcomes between boys in father-absent and father-present households is:

$$
\begin{gathered}
E\left(Y_{b} \mid D=1\right)-E\left(Y_{b} \mid D=0\right) \\
=E\left(Y_{b}(1) \mid D=1\right)-E\left(Y_{b}(0) \mid D=1\right)+E\left(Y_{b}(0) \mid D=1\right)-E\left(Y_{b}(0) \mid D=0\right)
\end{gathered}
$$

The first term is the average causal impact of father absence for boys raised in fatherabsent households; the second term is selection bias-the difference between potential outcomes in the father-present state between boys who were raised in that state and boys who were not. This will generally be non-zero, and any estimate of the effect of father absence will be biased if there are unobserved differences in child capabilities and mother characteristics in father-present and father-absent households. This is true for girls as well.

However, if the selection terms are identical for boys and girls, an estimate of the gender difference in the effects of father absence will be unbiased. If we have:

\section{Assumption 3.1 (Non-differential Selection)}

$$
E\left(Y_{b}(0) \mid D=1\right)-E\left(Y_{b}(0) \mid D=0\right)=E\left(Y_{g}(0) \mid D=1\right)-E\left(Y_{g}(0) \mid D=0\right)
$$

then the gender difference in the causal effects of father absence is identified (equation 3.1). Alternatively, we can define under Assumption 3.1 an unbiased estimate of the causal effect of father absence on gender gaps (equation 3.2).

$$
\begin{gathered}
{\left[E\left(Y_{b} \mid D=1\right)-E\left(Y_{b} \mid D=0\right)\right]-\left[E\left(Y_{g} \mid D=1\right)-E\left(Y_{g} \mid D=0\right)\right]} \\
=\left[E\left(Y_{b}(1) \mid D=1\right)-E\left(Y_{b}(0) \mid D=1\right)+E\left(Y_{b}(0) \mid D=1\right)-E\left(Y_{b}(0) \mid D=0\right)\right] \\
-\left[E\left(Y_{g}(1) \mid D=1\right)-E\left(Y_{g}(0) \mid D=1\right)+E\left(Y_{g}(0) \mid D=1\right)-E\left(Y_{g}(0) \mid D=0\right)\right] \\
=E\left(Y_{b}(1)-Y_{b}(0) \mid D=1\right)-E\left(Y_{g}(1)-Y_{g}(0) \mid D=1\right) \\
=E\left(Y_{b}(1)-Y_{g}(1) \mid D=1\right)-E\left(Y_{b}(0)-Y_{g}(0) \mid D=1\right)
\end{gathered}
$$

The main econometric specification in this paper is:

$$
Y_{i}=\alpha_{0}+\alpha_{1} \text { Male }_{i}+\alpha_{2} N F_{i}+\alpha_{3} O F_{i}+\beta_{1} \text { Male }_{i} \times N F_{i}+\beta_{2} \text { Male }_{i} \times O F_{i}+\gamma X_{i}+\varepsilon_{i}
$$


where $N F_{i}$ is a dummy variable equal to one if child $i$ lived in a household with no father figure in the baseline survey and $O F_{i}$ is equal to one if a non-biological, non-adoptive father, such as a step-father, lived in the household. $X_{i}$ includes maternal characteristics and the child's birth cohort. Standard errors are clustered by the school attended in Wave I. The coefficients of interest- $\beta_{1}$ and $\beta_{2}$-identify the gender difference in the causal effects of father absence and other father, under Assumption 3.1.

Therefore, the interpretation of the results as causal relies on the key identification assumption that selection into father absence and other father households is identical for boys and girls. Estimates may not be unbiased if father absence and child gender are not independent, and the fact that girls are more likely to live in father-absent households than boys raises the possibility of selection on child or maternal characteristics. One mechanism driving this gap may be parental decisions about marriage and custody that are child gender-specific: fathers are more likely to co-reside with, seek custody of, and marry the mothers of their sons rather than their daughters (Lundberg and Rose, 2003; Dahl and Moretti, 2008; Lundberg, 2005). Another may be through the effects of parental circumstances on the gender mix of offspring: evidence is mounting that prenatal stress (which may be related to partnership status) has differential impacts on the mortality of male and female fetuses, though the effects are small (Almond and Edlund, 2007; Hamoudi and Nobles, 2014, Norberg, 2004).

Table A4 presents a test for the identification assumption. If selection into father absent and other father households is identical for boys and girls, then the gaps in pre-determined characteristics between father-absent/other-father household and fatherpresent household should be the same for boys and girls. We do find that mother's characteristics and family income is often significantly associated with family structure, but there is no evidence that the selection is different across gender: none of the interaction terms are significantly different from $0 .{ }^{10}$ Another possible concern is selective attrition in this longitudinal study. We define attrition as the sample size reduction when conditioning on appearance in Wave IV (i.e. the change from column (4), Table A1 to column (5), Table A1). As shown in Column (8), Table A4, boys and adolescents in father-absent households are more likely to attrit before Wave IV, but attrition is not different across gender/family structure categories. These results indicate that there is no evidence that our identification assumption is violated in this sample. ${ }^{11}$

\footnotetext{
${ }^{10}$ Autor et al. (2019) and Brenøe and Lundberg (2018) show that there are no gender differences in the effects of family disadvantage on outcomes at birth, which suggests an absence of selection on child capability, but Add Health does not have similar early measures.

${ }^{11}$ We also did similar identification tests for NLSY97 sample (not reported here). None of the interaction terms is significantly different from 0 , and so there is also no evidence of violation of the identification assumption in this sample.
} 


\section{Results}

\subsection{Adolescent Outcomes}

Gender gaps in the behavior and achievements of school children in the Add Health sample are shown in Figure 1 for the three family structure groups: biological father present, no father, and other father. The gender gaps in the school problems index, depression index, school suspensions, and educational aspirations are relatively larger for respondents in non-traditional families. Therefore, Figure 1 provides some raw evidence that the effects of family structure on adolescent outcomes may differ by gender.

Figure 1: Gender Gaps in Adolescent Outcomes by Family Structures, Add Health Non-Hispanic White Sample

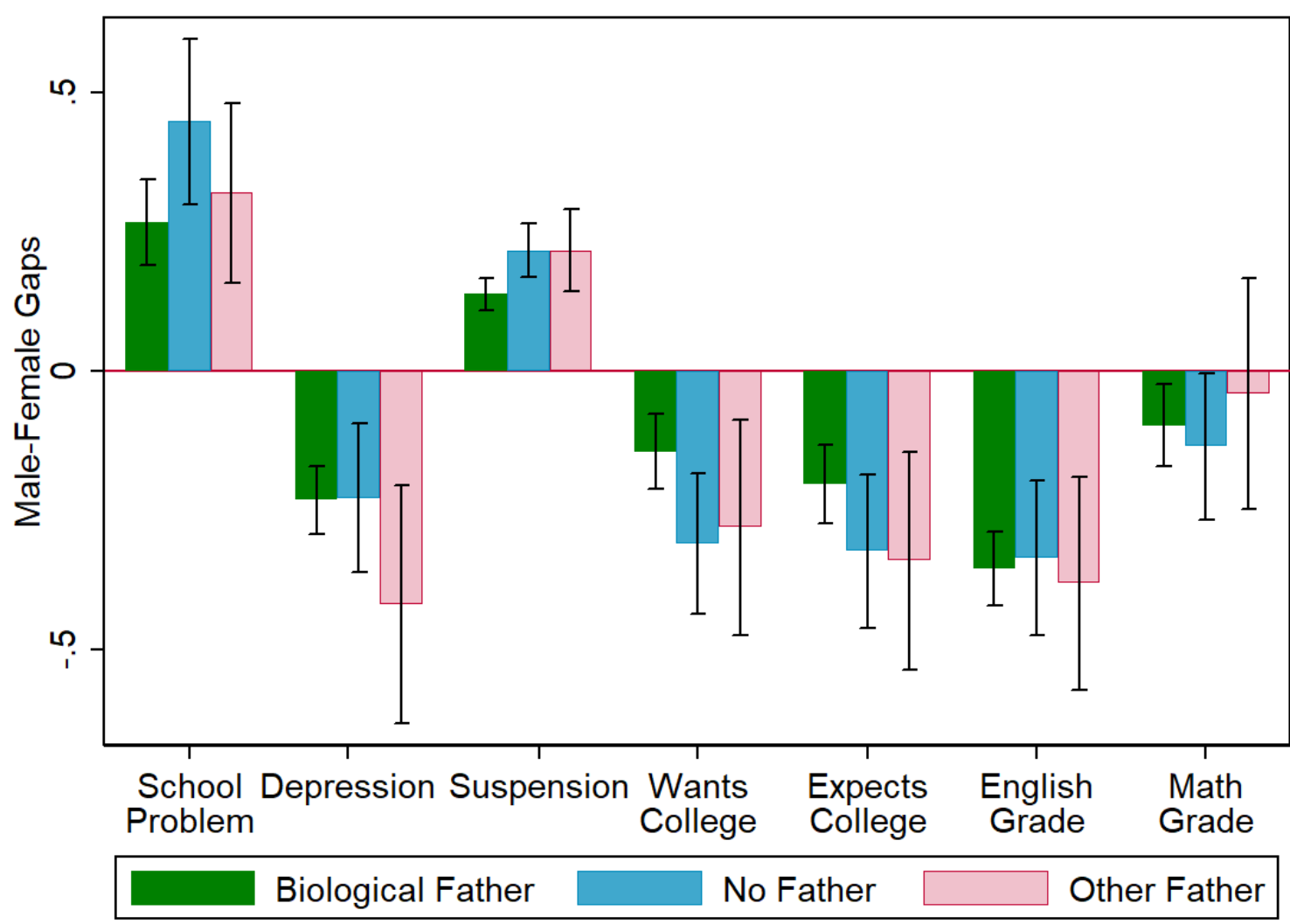

Note: This figure displays the coefficient of "Male" dummy, when regressing the outcomes on "Male" dummy and a constant, with its $95 \%$ confidence interval. "No Father" and "Other Father" refer to living arrangements at Wave I. "School problems" is a standardized index based on factor analysis of the variables in Table A5. "Depression" is a standardized index based on factor analysis of the variables in Table A6. Grades are student-reported and range from $1=\mathrm{D}$ or lower to $4=\mathrm{A}$. College desires/expectations are standardized measures based on a 0-4 scale. All models are weighted by Wave I weights.

Estimates of equation 3.3 showing the effects of father absence in Wave I on adolescent outcomes are reported in Table 1. Columns (1) and (2) show that living in a father absent household or step-father household is positively associated with school problems 
and school suspensions, and that this association (particularly for no-father households) is significantly greater for boys than for girls. ${ }^{12}$ The results for school suspensions in particular are strongly consistent with the findings of both Bertrand and Pan (2013) and Autor et al. (2019) ${ }^{13}$ In these results we see some evidence of differential male susceptibility to non-traditional family structures.

A different picture emerges when we look at another set of Wave I self-reports: depression in adolescence. Column (3) shows the effects of family structure on the depression index. Boys are significantly less likely than girls to report experiencing negative emotions, and youth in no-father and step-father families are more likely to make such reports. We find that depression is more strongly associated with living with a step-father or other father figure for girls than for boys, and the interaction term is also significant for several depression index components (Table A6). Depression is one example of an "internalizing" response to stress that is more common for girls, as opposed to the "externalizing" or disruptive behavior more typical of boys (Leadbeater, Kuperminc, Blatt, and Hertzog, 1999). ${ }^{14}$

Family structure does not appear to have any differential effect on self-reported grades in English and Math, though we find the usual pattern that boys' grades are lower than girls, particularly in English (Column (4)-(5), Table 1). When asked in Wave I about their college plans, Add Health boys are less likely than girls to report either that they want to attend college or that they expect to attend college (Column (6)-(7), Table 1). In this case, living in a household with no father appears to have a more severe effect on the college intentions of boys-they are substantially less likely to report a strong desire to attend college than girls in similar families.

The results in this section both reinforce and expand upon the findings of previous studies that show excess vulnerability of school-aged boys in the face of family disadvantage and father absence. The gender gap in school problems is much greater for adolescents who are not living with both biological parents, and this pattern is consistent with earlier studies that find increasing gender gaps in schools suspensions and externalizing behavior. Examining an aspect of problematic internalizing behavior, depression, indicates that girls may have distinctive responses to family disadvantage not reflected in standard measures of school achievement and disciplinary outcomes. These contrasting

\footnotetext{
${ }^{12}$ Table A5 shows the determinants of the school problems index and its components. Male students report higher incidence of all individual school difficulties except absences. The male/no-father interaction is significantly predictive of school suspensions, reported problems paying attention in school, and the overall school problems index.

${ }^{13}$ Bedard and Witman (2015) find that the gender gap in diagnosis and treatment of ADHD is much larger in non-traditional families, another result that suggests parents in traditional families may find it easier to cope with male behavioral difficulties in early life.

${ }^{14}$ Using the Add Health data, Slade and Beller (2013) also find a stronger association between nontraditional family structure in childhood and health outcomes, including depression, self-reported health and smoking, for girls. They also find that many of the effects of father absence on health and mental health outcomes in Wave I, including depression, are no longer significant in Wave IV.
} 


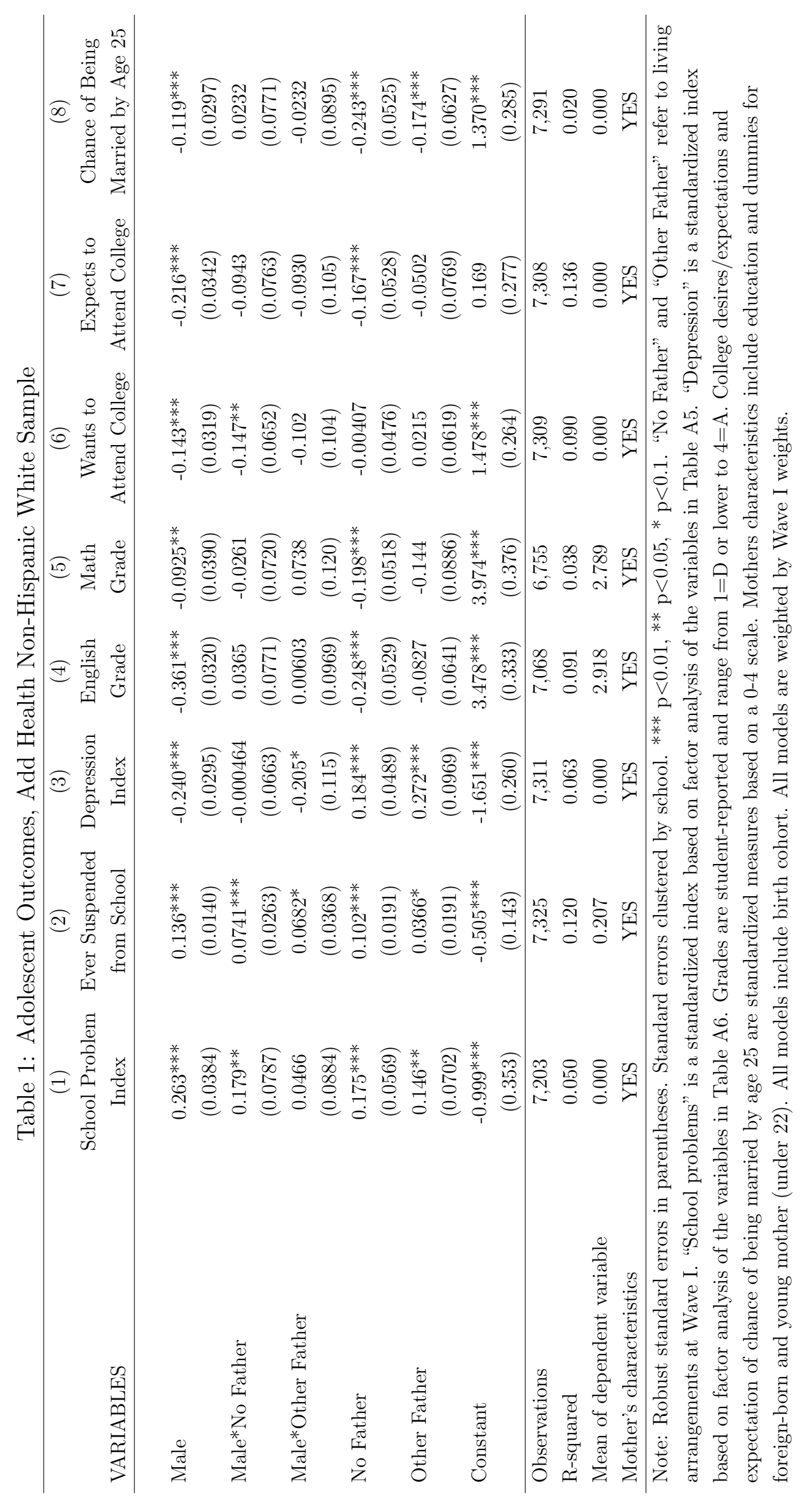


results show that our conclusions about which gender is more sensitive to father absence may depend on which school outcomes we are measuring.

What are the mechanisms underlying these results? One possible source of these differences may be sex differences in early developmental trajectories that have implications for skills in adolescence. Beginning in preschool, girls are more mature than boys in language skills and emotional regulation, and this may increase their resilience in some adverse circumstances. The absence of a stable, same-sex parent may also have distinct behavioral effects on boys, as the presence of a step-father appears to have for girls. ${ }^{15} \mathrm{~A}$ key implication here is that disadvantaged boys may be left with a deficit of skills, particularly non-cognitive skills, that can further disadvantage them in adulthood. In contrast, a cultural explanation is provided by DiPrete and Buchmann (2013), who argue that developing a masculine self-image may involve a rejection of school values, and that this oppositional culture may be particularly relevant for boys with absent or low-education fathers. The effects of father absence on boys' desire to attend college may provide some support for this mechanism.

Finally, parental investments in low-resource environments may differ by child gender. Though a large literature shows that, on average, fathers spend more time with sons than with daughters, and that this gap grows with age (Lundberg, 2005), Bertrand and Pan (2013) find that single mothers spend less time with sons than daughters and report less emotional closeness with sons in early school years. Such a result suggests a parental investment variant of the Trivers-Willard hypothesis from evolutionary biology: parents who are maximizing reproductive success invest more in male offspring in good conditions but more in females in poor conditions (Trivers and Willard, 1973). Explicit attempts to test for evidence of Trivers-Willard patterns in modern families, however, have not found it to be well-supported (Keller, Nesse, and Hofferth, 2001).

The Add Health survey has limited direct measures of parental inputs, but does include multiple indicators of the quality of the parent-child relationship, which may be related to parental investments. Adolescent reports in Wave I about their relationships with parents do not show any evidence of such distinctive boy-girl responses to father absence (Table A7). Children in father-absent families are less likely to report that their parents care about them, their family generally has fun, their mothers are warm and loving towards them, and they are satisfied with their relationship with their mother, but we find no significant gender differences in these family structure effects.

\subsection{Educational Attainment}

Do the gender-differential effects of father absence in adolescence persist into adulthood? The effects of father absence in adolescence on several measures of educational attainment from Wave IV of the Add Health Study, when the respondents are in their late twenties

\footnotetext{
${ }^{15}$ Others have argued that school environments, with predominantly female teachers, fail to adapt to the learning needs of boys (Dee, 2007).
} 
and early thirties, are reported in Tables 2-3. Table 2 shows that being male has a large negative effect on the probability that an Add Health respondent receives a 4-year college degree. In the initial model with no other covariates, the college gender gap is 7 percent and controlling for mothers characteristics (Columns (2)-(6)) has little effect on this gap. The coefficients on dummy variables for living in a family with no father figure or with a non-biological (step) father figure in Wave I are also large and negative.

Table 2: College Graduation, Add Health Non-Hispanic White Sample

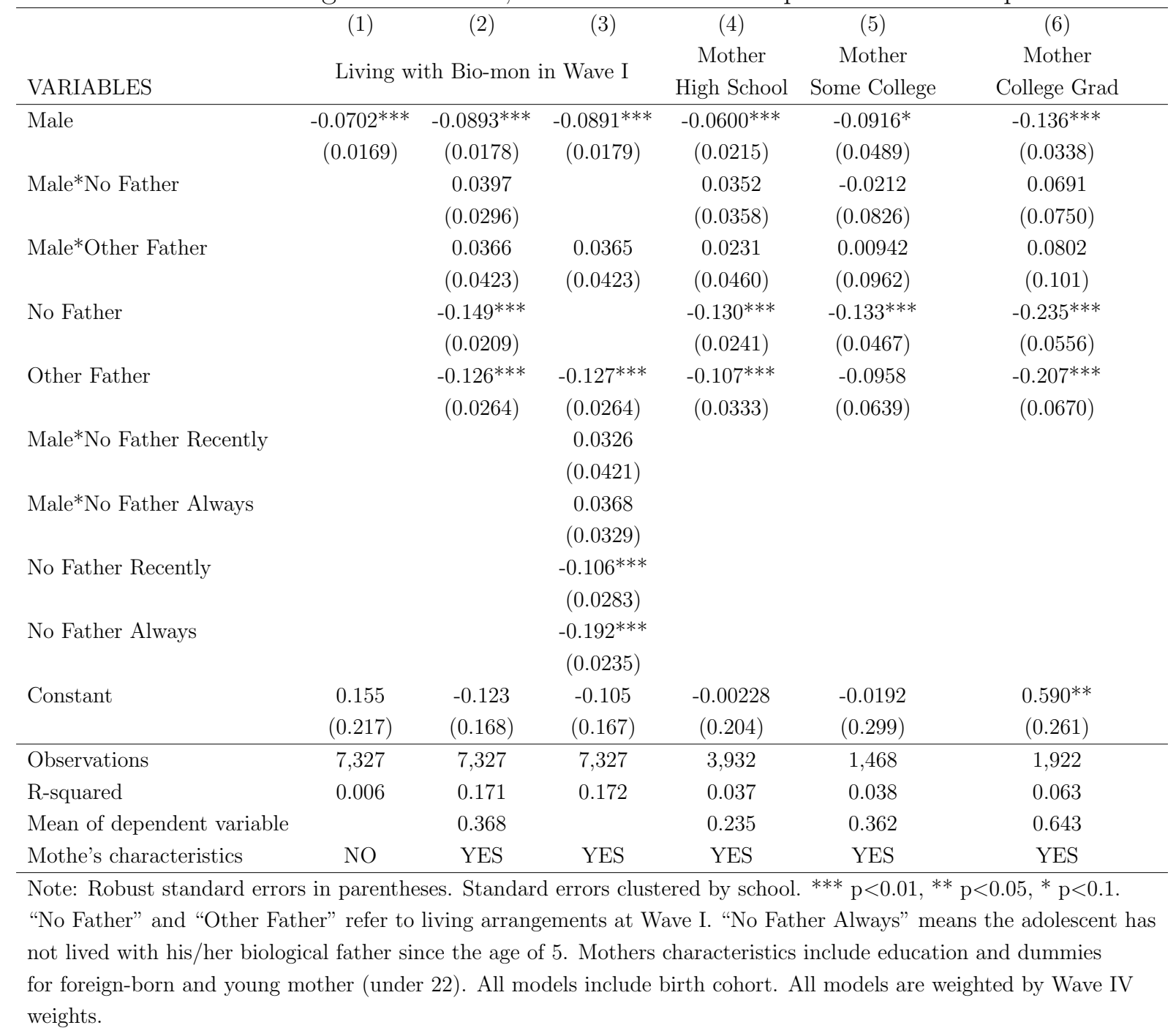

Non-traditional family structures do not, however, have differentially negative impacts on the college graduation rates of young men (Column (2)). The interaction effects, expected to be negative if boys are more vulnerable to father absence, are instead positive and insignificant. Column (3) decomposes the no father group into young adults who, though they did not live with their biological father at Wave I, did do so after the age of 5 (No Father Recently) and those who never lived with their father after age 5 (No Father Always). The latter status, as expected, has a larger negative association with college graduation but the gender interaction effects are once again positive, small and insignificant. Columns (4)-(6) report results from the core model for subsamples based 
on mother's education level, and the pattern is similar-negative effects of non-traditional family structures, but no evidence that the college graduation rates of men are more strongly affected by father absence than is college graduation by women.

The results in Table 3 show similar patterns in the determinants of high school graduation. Men are less likely to graduate from high school than women, living with no father or a step-father in Wave I has a strong negative association with graduation. There is weak support for greater male vulnerability to disadvantage: the interaction term of Male and No Father is marginally significant at the $10 \%$ level. The impact of father absence before age 5 (No Father Always) on men's high school graduation, compared to women's, is also marginally significant at a $10 \%$ level. Columns (4)-(6) split the sample by mother's education and show that the effects of family structure on men's high school graduation appear to be concentrated in families in which the mother had some college education, though none of the interaction terms are individually significantly in these subsamples.

Table 3: High School Graduation, Add Health Non-Hispanic White Sample

\begin{tabular}{|c|c|c|c|c|c|c|}
\hline VARIABLES & $\begin{array}{l}\text { (1) } \\
\text { with I }\end{array}$ & $\begin{array}{c}\text { (2) } \\
\text { Living } \\
\text { 3io-mom in } \mathrm{V}\end{array}$ & $\begin{array}{r}\text { (3) } \\
\text { Vave I }\end{array}$ & $\begin{array}{c}\text { (4) } \\
\text { Mother } \\
\text { High School }\end{array}$ & $\begin{array}{c}(5) \\
\text { Mother } \\
\text { Some College }\end{array}$ & $\begin{array}{c}\text { (6) } \\
\text { Mother } \\
\text { College Grad }\end{array}$ \\
\hline Male & $\begin{array}{c}-0.0251^{* * *} \\
(0.00821)\end{array}$ & $\begin{array}{c}-0.0235^{* * *} \\
(0.00837)\end{array}$ & $\begin{array}{c}-0.0235^{* * *} \\
(0.00837)\end{array}$ & $\begin{array}{l}-0.0258^{*} \\
(0.0151)\end{array}$ & $\begin{array}{l}-0.0110 \\
(0.0130)\end{array}$ & $\begin{array}{c}-0.0140 * * \\
(0.00576)\end{array}$ \\
\hline Male*No Father & & $\begin{array}{c}-0.0327^{*} \\
(0.0196)\end{array}$ & & $\begin{array}{l}-0.0298 \\
(0.0291)\end{array}$ & $\begin{array}{l}-0.0720 \\
(0.0452)\end{array}$ & $\begin{array}{l}-0.00242 \\
(0.0266)\end{array}$ \\
\hline Male*Other Father & & $\begin{array}{c}0.0171 \\
(0.0272)\end{array}$ & $\begin{array}{c}0.0170 \\
(0.0273)\end{array}$ & $\begin{array}{c}0.0433 \\
(0.0484)\end{array}$ & $\begin{array}{l}-0.0171 \\
(0.0360)\end{array}$ & $\begin{array}{l}-0.0203 \\
(0.0310)\end{array}$ \\
\hline No Father & & $\begin{array}{c}-0.0336^{* *} \\
(0.0129)\end{array}$ & & $\begin{array}{c}-0.0592^{* * *} \\
(0.0209)\end{array}$ & $\begin{array}{l}-0.0257 \\
(0.0181)\end{array}$ & $\begin{array}{c}-0.0124 \\
(0.00969)\end{array}$ \\
\hline Other Father & & $\begin{array}{c}-0.0379^{* *} \\
(0.0176)\end{array}$ & $\begin{array}{c}-0.0380^{* *} \\
(0.0176)\end{array}$ & $\begin{array}{c}-0.0663^{* *} \\
(0.0324)\end{array}$ & $\begin{array}{l}0.00108 \\
(0.0178)\end{array}$ & $\begin{array}{l}0.000956 \\
(0.00198)\end{array}$ \\
\hline Male*No Father Recently & & & $\begin{array}{l}-0.0116 \\
(0.0240)\end{array}$ & & & \\
\hline Male*No Father Always & & & $\begin{array}{c}-0.0597^{*} \\
(0.0332)\end{array}$ & & & \\
\hline No Father Recently & & & $\begin{array}{c}-0.0293^{*} \\
(0.0155)\end{array}$ & & & \\
\hline No Father Always & & & $\begin{array}{l}-0.0380 * \\
(0.0204)\end{array}$ & & & \\
\hline Constant & $\begin{array}{c}0.796^{* * *} \\
(0.0859)\end{array}$ & $\begin{array}{c}0.607^{* * *} \\
(0.0774)\end{array}$ & $\begin{array}{c}0.612^{* * *} \\
(0.0788)\end{array}$ & $\begin{array}{c}0.761^{* * *} \\
(0.117)\end{array}$ & $\begin{array}{c}0.809^{* * *} \\
(0.126)\end{array}$ & $\begin{array}{c}0.906^{* * *} \\
(0.0497)\end{array}$ \\
\hline Observations & 7,327 & 7,327 & 7,327 & 3,932 & 1,468 & 1,922 \\
\hline R-squared & 0.003 & 0.080 & 0.081 & 0.023 & 0.032 & 0.012 \\
\hline Mean of dependent variable & & 0.935 & & 0.900 & 0.958 & 0.988 \\
\hline Mother's characteristics & NO & YES & YES & YES & YES & YES \\
\hline \multicolumn{7}{|c|}{$\begin{array}{l}\text { Note: Robust standard errors in parentheses. Standard errors clustered by school. }{ }^{* * *} \mathrm{p}<0.01,{ }^{* *} \mathrm{p}<0.05,{ }^{*} \mathrm{p}<0.1 \text {. } \\
\text { "No Father" and "Other Father" refer to living arrangements at Wave I. "No Father Always" means the adolescent has } \\
\text { not lived with his/her biological father since the age of } 5 \text {. Mothers characteristics include education and dummies } \\
\text { for foreign-born and young mother (under } 22 \text { ). All models include birth cohort. All models are weighted by Wave IV } \\
\text { weights. }\end{array}$} \\
\hline
\end{tabular}

Table A8 reports the results of key models for two alternative measures: years of completed education and a categorical measure of educational attainment that ranges 
from $0=$ less than high school to $5=$ post-graduate degree. The pattern of coefficients is very similar to that for college graduation: substantial negative effects of being male and living without a father in adolescence, but no differential impacts of family structure by gender.

In general, the evidence from the Add Health cohorts of young adults strongly suggests that, though being male and living in a household without a biological father in adolescence are negatively associated with educational attainment, young men do not appear to be differentially affected by father absence when we focus on long-term outcomes such as college graduation. There is some limited evidence that high school graduation, which is likely to be more directly affected than college graduation by grade school achievement and misbehavior, may be a hurdle for which father presence is more important for boys.

\subsection{Other Adult Outcomes: Labor Market, Family, and Mental Health}

Gender gaps in key adult outcomes for different family structures are shown in Figure 2. Most gender gaps are prevalent across all types of family, though gaps for family outcomes appear to be larger for respondents who grew up in non-traditional families. Table 4 reports the estimated effects of father absence in adolescence on adult outcomes.

In general, growing up in a father-absent or a step-father household is associated with negative labor market and other economic outcomes for both men and women, including employment, income, job satisfaction, job terminations, and a measure of financial stress (Columns (1)-(5)). However, for most of these outcomes, the effects do not differ significantly by gender. One exception is that, though other father figures have a weakly negative association with the likelihood of being currently employed for women, this is not true for men: the stepfather-male interaction term is positive and significant at the $5 \%$ level. Also, the negative effect of a no-father household on financial stress is significantly smaller for men than for women. This evidence shows that the effects of non-traditional family structure on most labor market outcomes, as with educational attainment, do not differ across genders. When they do differ, it is to the benefit of men rather than women.

Men typically marry at later ages than women, and we find that male Add Health respondents are less likely to have ever been married than female respondents at the same age (Column 6) and also report fewer children (Column 7). Marriage probabilities for women who grew up in father-absent and step-father households are not significantly different from those in bio-father households, but father absence is associated with a lower likelihood of being ever married for men. Gender differences also emerge for the number of reported children ever born: father absence and other father figures are significantly associated with more births for women and, since marriage probabilities remain unchanged, many of these are likely to be non-marital births. These positive effects are offset for men by the negative coefficients on the interaction terms, however, indicating that family 


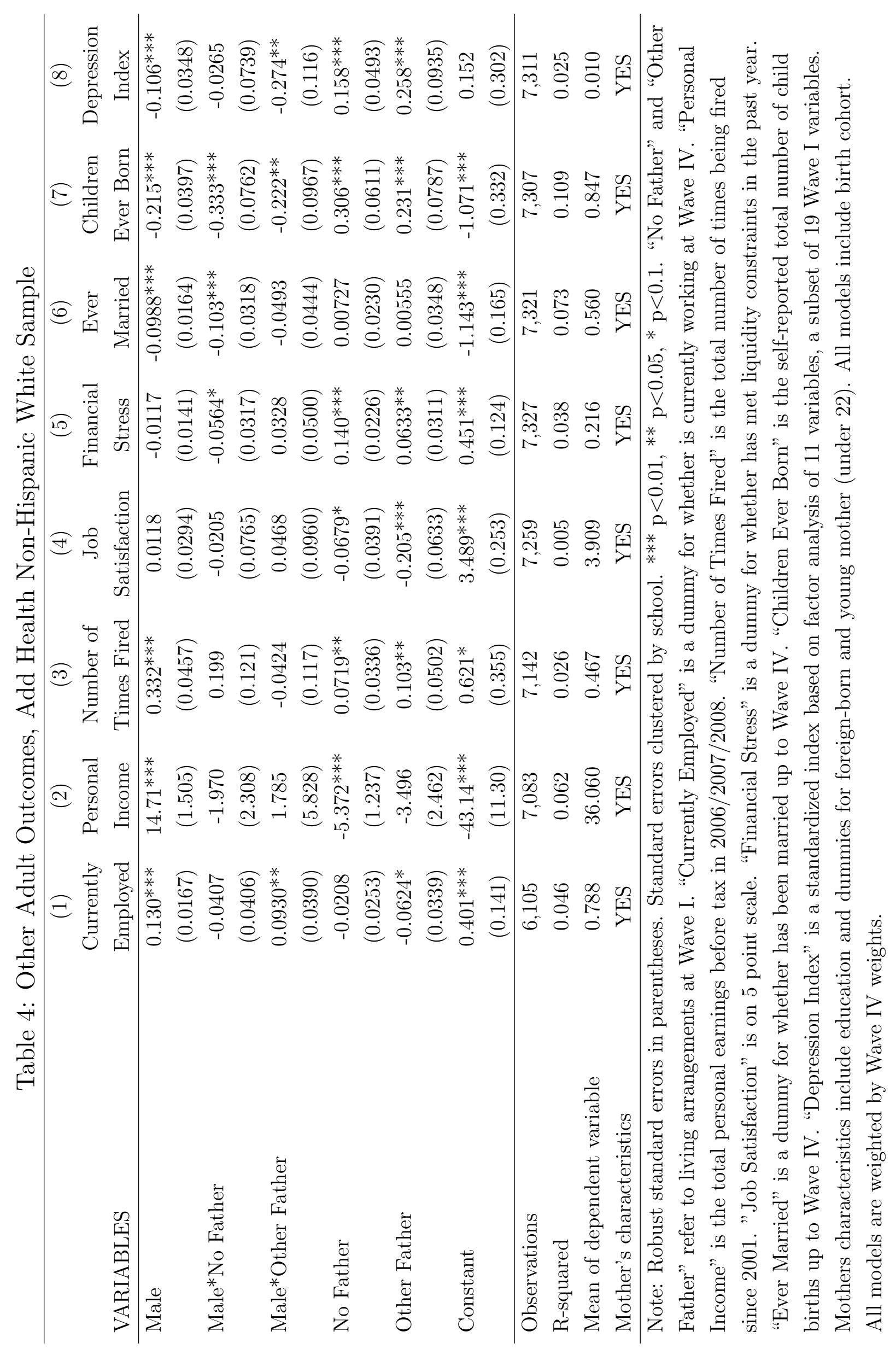


Figure 2: Gender Gaps in Adult Outcomes by Family Structures, Add Health Non-Hispanic White Sample

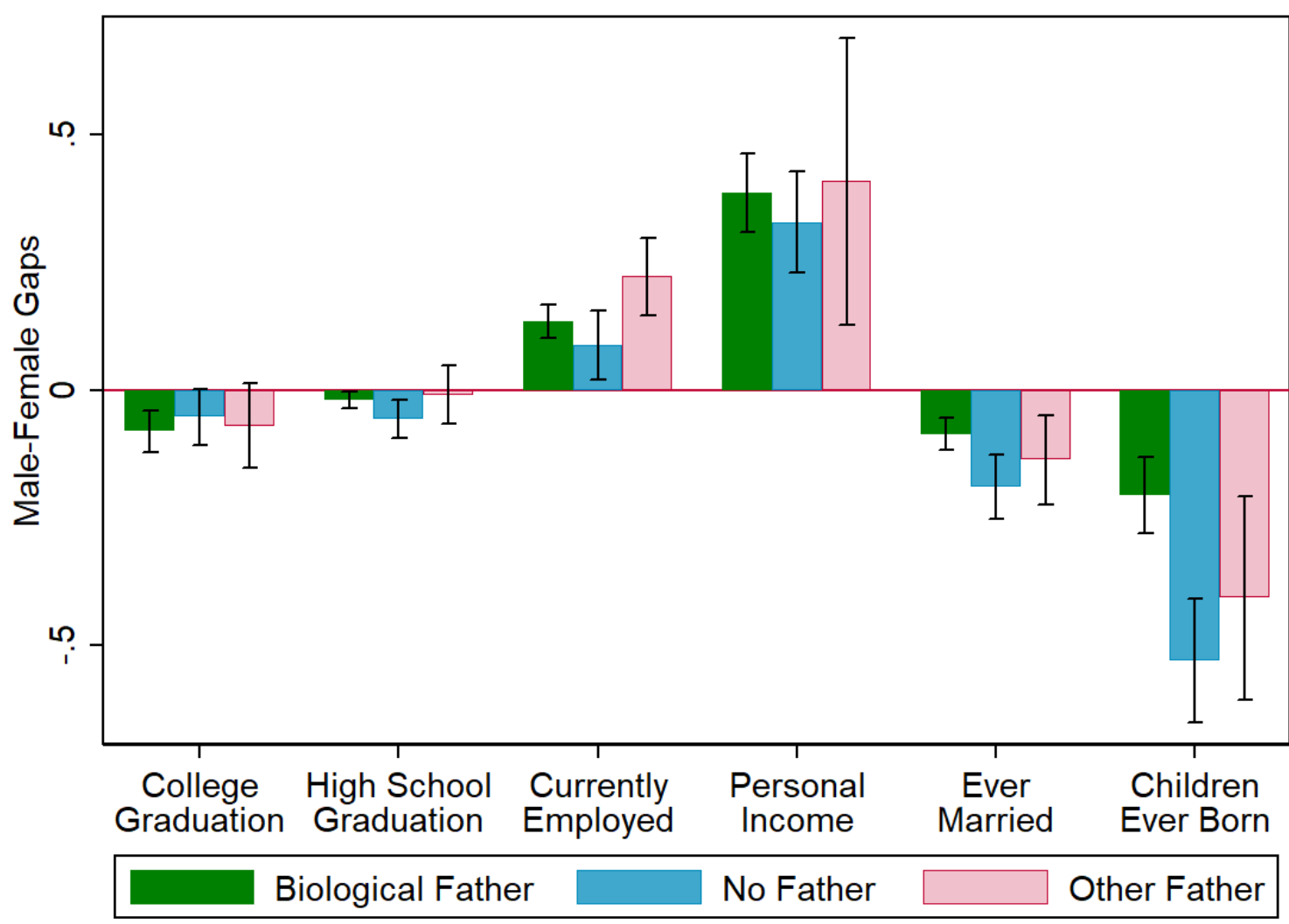

Note: This figure displays the coefficient of "Male" dummy, when regressing the outcomes on "Male" dummy and a constant, with its $95 \%$ confidence interval. "No Father" and "Other Father" refer to living arrangements at Wave I. "Currently Employed" is a dummy for whether is currently working at Wave IV. "Personal Income" is the total personal earnings before tax in 2006/2007/2008. "Ever Married" is a dummy for whether has been married up to Wave IV. "Children Ever Born" is the self-reported total number of child births up to Wave IV. All models are weighted by Wave IV weights.

background has no apparent effect on fertility for men. This reduction in marriage for men and increased fertility for women are generally consistent with Anderson (2017), who finds that adverse childhood environments are associated with increased sexual risk behaviors and greater likelihood of living in an unmarried couple for both men and women.

One possible mechanism for these effects on family dynamics is that non-traditional family structure in adolescence differentially changes the preferences and expectations about family formation and stability for boys and girls, and these gender differences persist into adulthood. An alternative explanation is that non-traditional family structure is associated with more negative marriage market characteristics, especially for men. Column (8), Table 1 provides some evidence that fails to support the former hypothesis. Although non-traditional family structure is negatively associated the Wave I reports regarding their chances of being married at age 25, the effects are not different across gender. Therefore, self-reports in adolescence do not indicate that the effects come from changes 
in marriage aspirations that differ between boys and girls. This is consistent with the findings of Kamp Dush, Arocho, Mernitz, and Bartholomew (2018), who attribute intergenerational correlations of partnering behaviors to the transmission of poor marriageable characteristics and relationship skills. ${ }^{16}$

Non-traditional family structure is associated with higher levels of depression in adulthood (Column 8). In addition, the association between step-father households and depression, which was positive for girls but not for boys in adolescence, appears to be a pattern that persists into adulthood.

The key takeaway from these analyses is that, though the absence of a biological father appears to have some persistent effects that differ by gender, particularly for family formation in adulthood, these effects do not fall readily into a vulnerable boys framework. There are few gendered effects on economic and labor market outcomes, but these tend to disadvantage women, and step-father families have a persistent association with depression in adulthood only for women.

\subsection{School Quality and Neighborhood Effects}

The "male vulnerability" hypothesis has been studied primarily in terms of adolescent responses to family disadvantage, but Autor et al. (2019) have also found that boys appear to be more sensitive than girls to variations in school quality and neighborhood characteristics in terms of test scores, absences, and suspensions, though these environmental factors explain only a small portion of the family SES contribution to this gap.

The estimates in Table 5 examine whether the short-run and long-run outcomes of male students in Add Health are more responsive to variations in school quality than are outcomes for female students. The school quality index is strongly associated with a lower probability of school suspension, higher educational aspirations, higher grades in adolescence, higher high school and college graduation rates, and lower fertility. For adolescent outcomes, some of the gender interaction effects are also significant. The gender gaps in the college attendance desires and expectations and in school suspensions are much smaller in high-quality schools. In other words, boys are indeed more responsive to school quality than girls in terms of educational aspirations and suspensions. However, as with father absence, these differential effects do not appear to have implications for eventual educational attainment, including high school and college graduation, employment, income and marriage. The only exception among adult outcomes is fertility: though the number of births by Wave IV is significantly reduced by higher school quality for women, the reported fertility of males is much less responsive to school quality.

Table 6 investigates whether neighborhood effects are different across gender, for shortrun and long-run outcomes. The proportion of highly-educated people in the neighbor-

\footnotetext{
${ }^{16}$ If the gender difference in marital behavior reflects a more general increase in relationship instability for young men, then some part of the apparent gender gap in the fertility effects of father absence may be due to underreporting of children not born into committed relationships.
} 


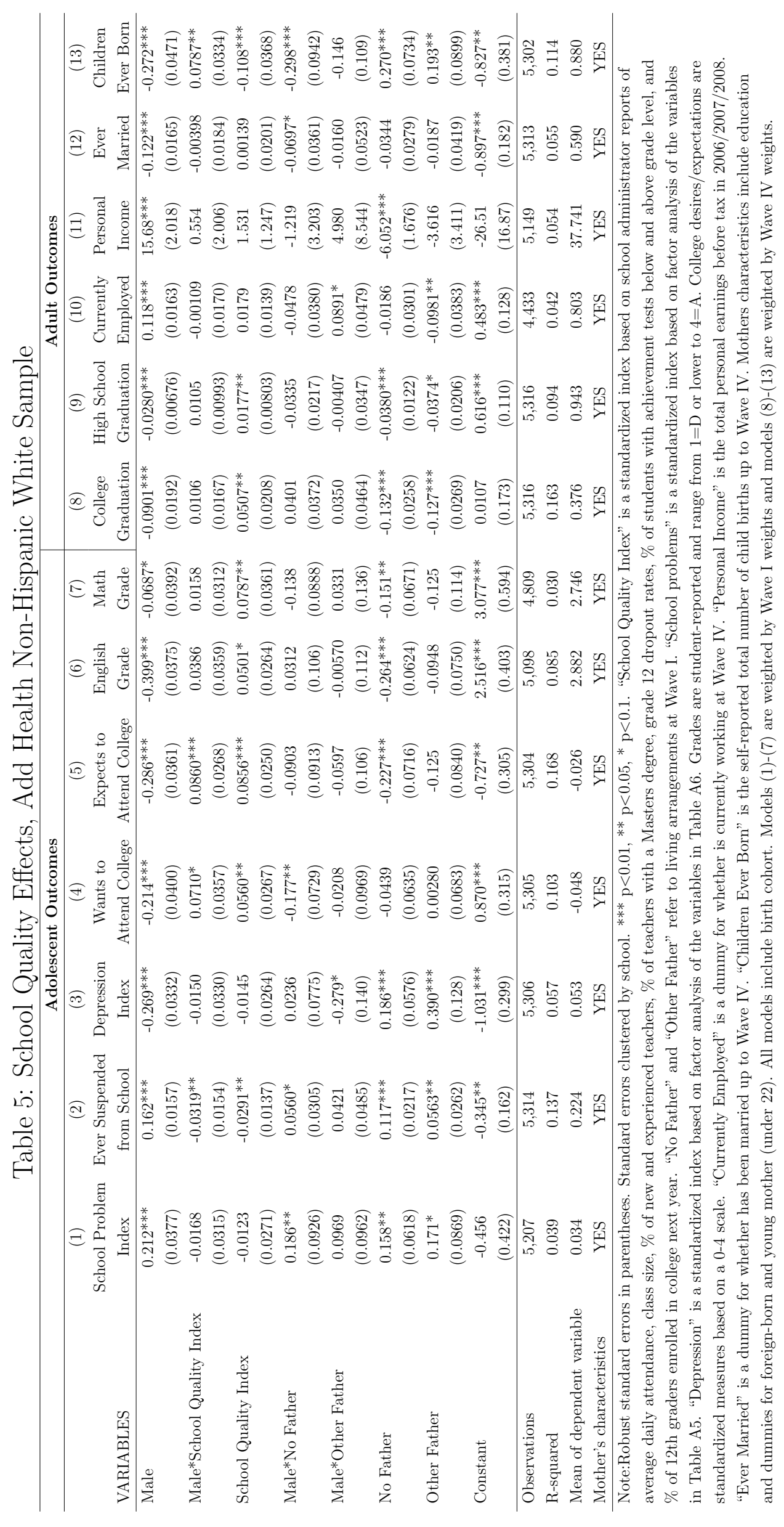


hood adolescents live in is strongly associated with fewer suspensions, higher educational aspirations, and higher math grades in adolescence, and with higher high school and college graduation rates, higher income, higher employment probabilities, lower probabilities of marriage, and fewer births in adulthood. In adolescence, the educational aspirations of boys are significantly more responsive to neighborhood quality than those of girls. There is also some evidence that the relative math grades of girls are higher in highly-educated neighborhoods. These results indicate that a highly-educated neighborhood boosts the aspirations for higher education for boys relative to girls, but improves the math performance of girls relative to boys. These differential neighborhood effects don't persist into adulthood for college graduation, employment, income and marriage, but there is some evidence that an educated neighborhood benefits boys more than girls in terms of high school graduation. In addition, the fertility decisions of men are less responsive to neighborhood quality than women's, as is the case with school quality effects.

Table A9 presents results from models that include both school quality and neighborhood effects. The results are robust, implying that although school quality and neighborhood education levels are correlated, they have different patterns of effects. In general, school quality and neighborhood effects on some adolescent outcomes, especially educational aspirations, suspension and math grades, differ across genders, implying that boys are more responsive to advantages/disadvantages in adolescence. However, as with father absence, the differential effects vanish in adulthood, except for fertility decisions.

\subsection{Additional Results}

\subsubsection{Add Health Black Sample}

The African-American sample in Add Health is much smaller than the non-Hispanic white sample (about 2700 vs. 7200), but the higher prevalence of non-traditional families in this population makes a parallel analysis of key outcomes on this subsample potentially informative. On some dimensions, the results reported in Table A10 contrast sharply with those from the majority sub-sample. Young Black men are less likely to graduate from high school or college than young Black women (and by larger margins than in the white sample) and no-father households are still associated with less education, more school problems, and a higher probability of school suspension. However, in important departures from the white sample results, there are no significant gender or family structure effects on college aspirations, and no family structure effects on the depression index. There is only one significant gender/family structure interaction, and it is a surprising one. The gender gap in school suspensions is smaller for adolescents in no-father families, rather than larger. In general, school discipline rates are much higher for Black students, male and female, and the behavioral determinants appear to be very different as well. The differences between the Black and white samples on this dimension may be reflective of racial differences in the institutions of school discipline. 


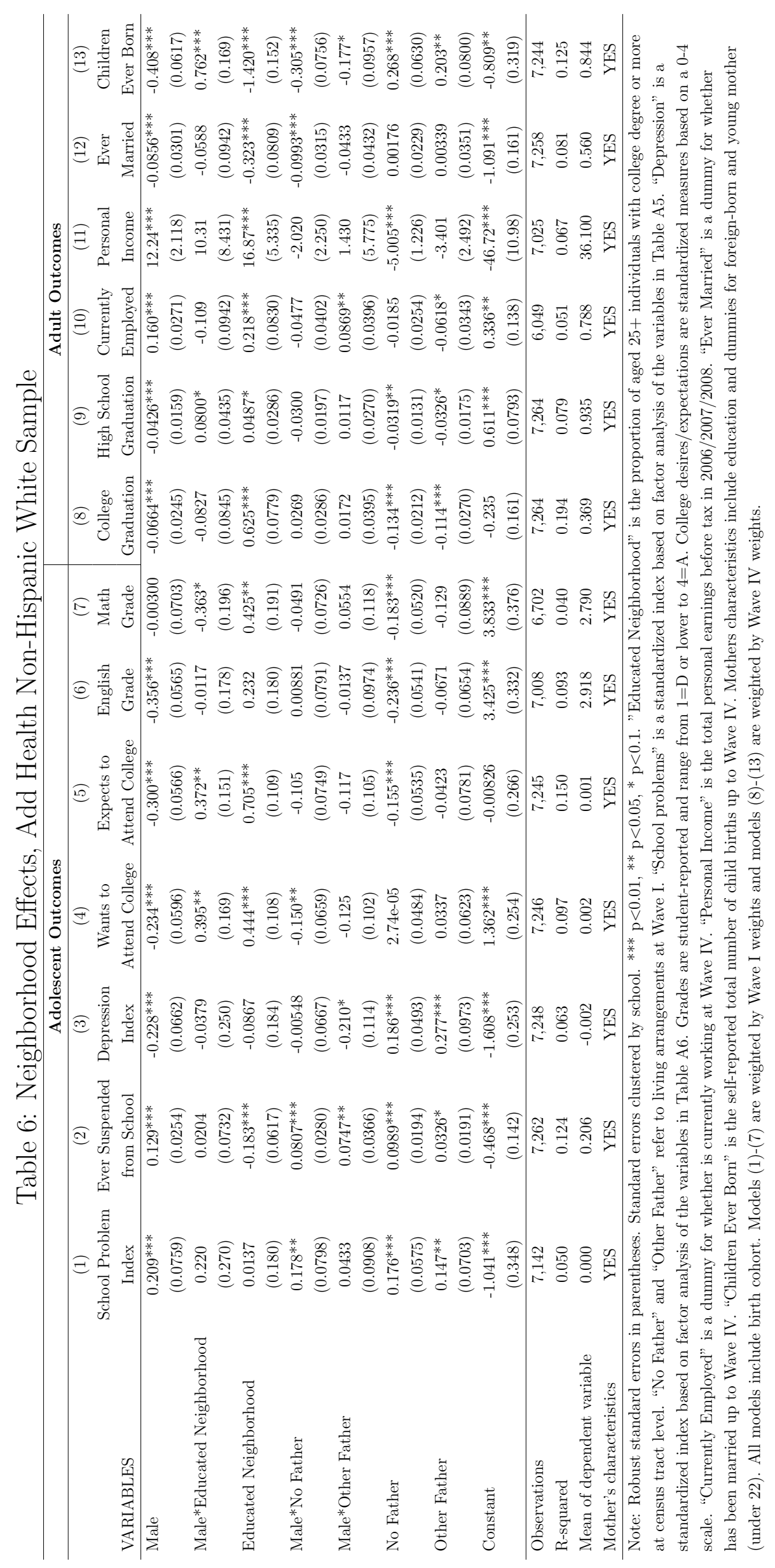




\subsubsection{NLSY97 White Non-Hispanic Sample}

In order to examine the external validity of our results, we replicate the main analysis using another representative longitudinal dataset, NLSY97. The results for adult outcomes are reported in Table 7. Most results are consistent with those from the Add Health sample. Father absence has no differential effect on high school and college graduation, personal income and job satisfaction for NLSY97 men and women. Step-father households, in one departure from the Add Health results, have less negative impacts on college graduation for men than for women, though they do have a marginally significant negative effect on the job satisfaction of men compared to women. Non-traditional family structures tend to increase the likelihood of being currently employed for men relative to women and to decrease the likelihood of being ever married and fertility more for men, as in Add Health. In addition, there is some evidence that other father figures increase depression in adulthood less for males relative to females, which is also consistent with the Add Health results. Table A11 reports estimates using alternative measures of educational attainment, and these results also support the robustness of our Add Health findings. In general, the results using NLSY97 sample support a conclusion that non-traditional family structures have few differential impacts on educational attainment across gender and any significant effects tend to be in favor of males rather than females. This implies that the apparent excess vulnerability of adolescent boys in school-based behaviors doesn't persist into adulthood.

\section{Conclusion}

Using data on young cohorts of men and women from the National Longitudinal Study of Adolescent to Adult Health, we investigate the association between economic disadvantage in adolescence and relative outcomes for men and women, both in school and later in life. Girls appear more resilient to father absence when the outcomes are adolescent school problems, suspensions, and educational aspirations, while boys appear more resilient to father absence when we examine depression. Though these school-age outcomes are themselves associated with poor educational and labor market outcomes in adulthood, these gender gaps related to father absence do not result in differential college graduation rates, income or other adult economic outcomes. The principal exceptions are marriage and reported fertility: non-traditional family structures are associated with lower relative probabilities of marriage and number of children for men, compared to women. The pattern of results is similar when boy/girl vulnerability to poor school quality or less educated neighborhoods, instead of father absence, is examined. Additional results using another representative longitudinal dataset, the National Longitudinal Survey of Youth 1997, show very similar patterns as well.

These mixed results - gender-specific behavioral responses to family disadvantage among school children that do not result in gendered consequences for eventual educational at- 


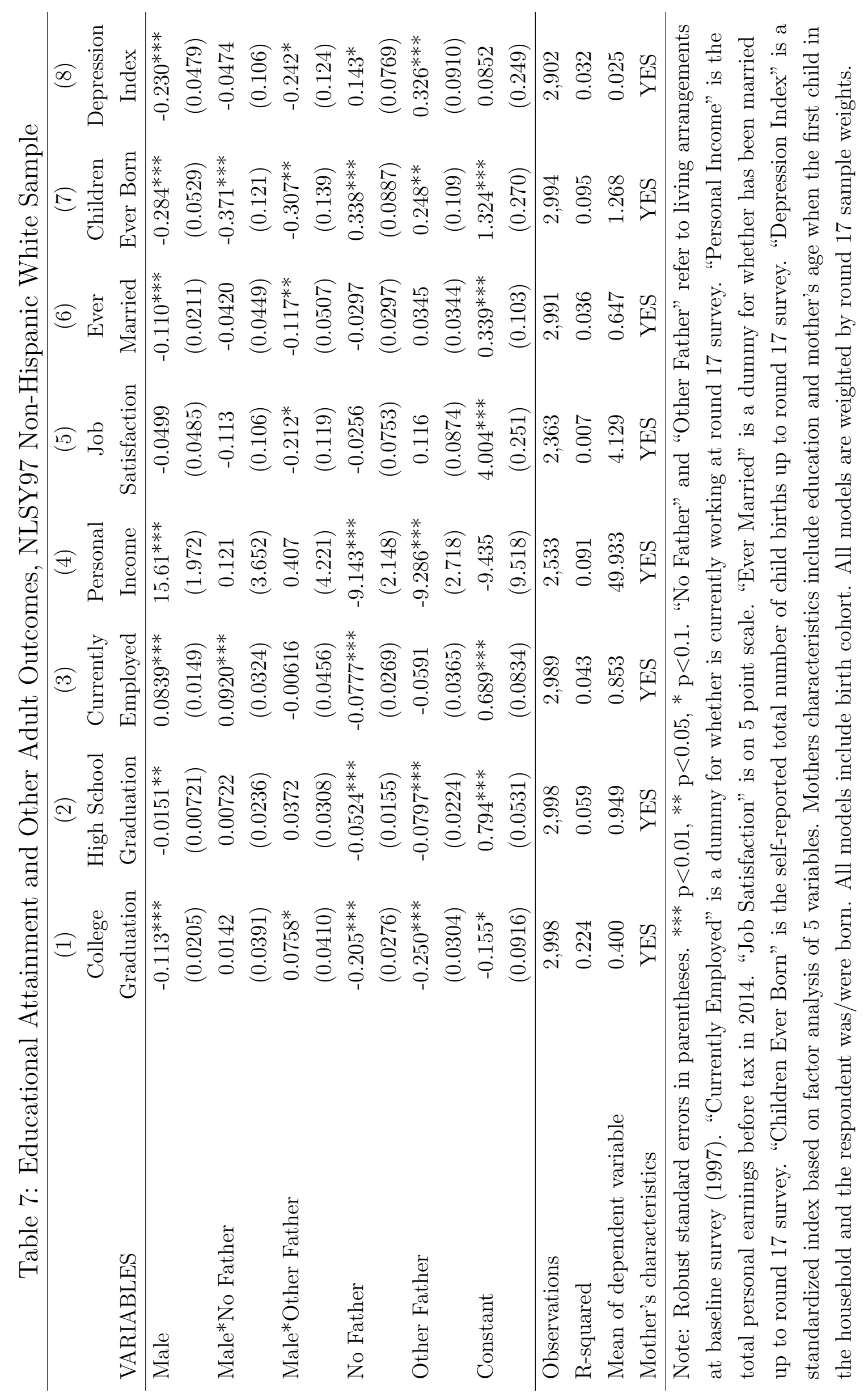


tainment and other economic outcomes - suggest that previous findings of excess male vulnerability, while provocative and interesting, can be over-interpreted. Measures of problem behaviors in school seem to reflect gendered responses to disadvantage and they do not have clear implications for actual skill development in boys and girls or for eventual educational outcomes. Behavior in school is a consequence, not just of underlying skills and traits, but also of constraints and expectations that operate very differently for boys and girls due to gender norms in behavior on the part of parents, teachers, and the children themselves. Externalizing behavior that leads to problems in school is much more prevalent among boys, while internalizing behavior, which includes anxiety and depression, is a more common response to stress for girls, but is not included in the survey and administrative data used in prior studies. Most of the socio-behavioral outcomes examined in other studies, such as kindergarten readiness and school suspensions, are also related to externalizing behavior and so suggest greater male vulnerability to disadvantage. This analysis of Add Health data, though consistent with these earlier studies, finds no evidence supporting the hypothesis that disadvantages in adolescence have contributed to the growing gender gap in college graduation, or to gender gaps in other adult economic outcomes. 


\section{References}

[1] Almond, Douglas, and Lena Edlund. "Trivers-Willard at birth and one year: evidence from US natality data 1983-2001." Proceedings of the Royal Society B: Biological Sciences 274, no. 1624 (2007): 2491-2496.

[2] Amato, Paul R., and Joan G. Gilbreth. "Nonresident fathers and children's well-being: A meta-analysis." Journal of Marriage and the Family (1999): 557-573.

[3] Anderson, Kermyt G. "Adverse childhood environment: relationship with sexual risk behaviors and marital status in a large American sample." Evolutionary Psychology 15, no. 2 (2017): 1474704917710115.

[4] Autor, David, and Melanie Wasserman. "Wayward sons: The emerging gender gap in labor markets and education." Third Way Report (2013).

[5] Autor, David, David Figlio, Krzysztof Karbownik, Jeffrey Roth, and Melanie Wasserman. 2019. "Family Disadvantage and the Gender Gap in Behavioral and Educational Outcomes." American Economic Journal: Applied Economics, 11 (3): 338-81.

[6] Bailey, Martha J. and Susan Dynarski. "Inequality in Postsecondary Education" (with Susan Dynarski). In G.J. Duncan and R.J. Murnane (eds.), Whither Opportunity? Rising Inequality, Schools, and Childrens Life Chances. (Russell Sage: New York, New York, September 2011).

[7] Becker, Gary S., William HJ Hubbard, and Kevin M. Murphy. "Explaining the worldwide boom in higher education of women." Journal of Human Capital 4, no. 3 (2010): 203-241.

[8] Bedard, Kelly, and Allison Witman. "Family structure and the gender gap in ADHD." Unpublished Manuscript (2015).

[9] Bertrand, Marianne, and Jessica Pan. "The trouble with boys: Social influences and the gender gap in disruptive behavior." American Economic Journal: Applied Economics 5, no. 1 (2013): 32-64.

[10] Brenøe, Anne Ardila, and Shelly Lundberg. "Gender gaps in the effects of childhood family environment: Do they persist into adulthood?." European Economic Review 109 (2018): 42-62.

[11] Buchmann, Claudia, Thomas A. DiPrete, and Anne McDaniel. "Gender inequalities in education." Annu. Rev. Sociol 34 (2008): 319-337.

[12] Chetty, Raj, and Nathaniel Hendren. "The impacts of neighborhoods on intergenerational mobility I: Childhood exposure effects." The Quarterly Journal of Economics 133, no. 3 (2018): 1107-1162. 
[13] Chetty, Raj, Nathaniel Hendren, Frina Lin, Jeremy Majerovitz, and Benjamin Scuderi. "Childhood environment and gender gaps in adulthood." American Economic Review 106, no. 5 (2016): 282-88.

[14] Dahl, Gordon B., and Enrico Moretti. "The demand for sons." The Review of Economic Studies 75, no. 4 (2008): 1085-1120.

[15] Dee, Thomas S. "Teachers and the gender gaps in student achievement." Journal of Human resources 42, no. 3 (2007): 528-554.

[16] DiPrete, Thomas A., and Claudia Buchmann. The rise of women: The growing gender gap in education and what it means for American schools. Russell Sage Foundation, 2013.

[17] DiPrete, Thomas A., and Jennifer L. Jennings. "Social and behavioral skills and the gender gap in early educational achievement." Social Science Research 41, no. 1 (2012): 1-15.

[18] Dougherty, Christopher. "Why are the returns to schooling higher for women than for men?." Journal of Human Resources 40, no. 4 (2005): 969-988.

[19] Duckworth, Angela Lee, and Martin EP Seligman. "Self-discipline gives girls the edge: Gender in self-discipline, grades, and achievement test scores." Journal of educational psychology 98, no. 1 (2006): 198.

[20] Dush, Claire M. Kamp, Rachel Arocho, Sara Mernitz, and Kyle Bartholomew. "The intergenerational transmission of partnering." PloS one 13, no. 11 (2018): e0205732.

[21] Fan, Xiaodong, Hanming Fang, and Simen Markussen. "Mothers' Employment and Children's Educational Gender Gap." No. w21183. National Bureau of Economic Research, 2015.

[22] Fahle, Erin M. and Sean F. Reardon. "Education." In "State of the Union: The Poverty and Inequality Report." Special issue, Pathways Magazine (2018).

[23] Fortin, Nicole M., Philip Oreopoulos, and Shelley Phipps. "Leaving boys behind gender disparities in high academic achievement." Journal of Human Resources 50, no. 3 (2015): 549-579.

[24] Goldin, Claudia, Lawrence F. Katz, and Ilyana Kuziemko. "The homecoming of American college women: The reversal of the college gender gap." Journal of Economic perspectives 20, no. 4 (2006): 133-156.

[25] Gould, Eric D., Victor Lavy, and M. Daniele Paserman. "Sixty years after the magic carpet ride: The long-run effect of the early childhood environment on social and economic outcomes." The Review of Economic Studies 78, no. 3 (2011): 938-973. 
[26] Hamoudi, Amar, and Jenna Nobles. "Do daughters really cause divorce? Stress, pregnancy, and family composition." Demography 51, no. 4 (2014): 1423-1449.

[27] Hetherington, Eileen Mavis, and John Kelly. For better or for worse: Divorce reconsidered. WW Norton \& Company, 2002.

[28] Jacob, Brian A. "Where the boys aren't: Non-cognitive skills, returns to school and the gender gap in higher education." Economics of Education review 21, no. 6 (2002): 589-598.

[29] Keller, Matthew C., Randolph M. Nesse, and Sandra Hofferth. "The TriversWillard hypothesis of parental investment: no effect in the contemporary United States." Evolution and Human Behavior 22, no. 5 (2001): 343-360.

[30] Leadbeater, Bonnie J., Gabriel P. Kuperminc, Sidney J. Blatt, and Christopher Hertzog. "A multivariate model of gender differences in adolescents' internalizing and externalizing problems." Developmental psychology 35, no. 5 (1999): 1268.

[31] Lopoo, Leonard M., and Thomas DeLeire. "Family structure and the economic wellbeing of children in youth and adulthood." Social Science Research 43 (2014): 30-44.

[32] Lundberg, Shelly. "Sons, daughters, and parental behaviour." Oxford Review of Economic Policy 21, no. 3 (2005): 340-356.

[33] Lundberg, Shelly. "Father Absence and the Educational Gender Gap." IZA Working Paper No. 18014, May 2017 (2017a).

[34] Lundberg, Shelly. "Non-cognitive skills as human capital." In Education, Skills, and Technical Change: Implications for Future US GDP Growth. University of Chicago Press, 2017 (2017b).

[35] Lundberg, Shelly, and Elaina Rose. "Child gender and the transition to marriage." Demography 40, no. 2 (2003): 333-349.

[36] Manuck, Stephen B., and Jeanne M. McCaffery. "Gene-environment interaction." Annual review of psychology 65 (2014): 41-70.

[37] McLanahan, Sara, and Gary Sandefur. Growing Up with a Single Parent. What Hurts, What Helps. Harvard University Press, 79 Garden Street, Cambridge, MA 02138, 1994.

[38] Norberg, Karen. "Partnership status and the human sex ratio at birth." Proceedings of the Royal Society of London. Series B: Biological Sciences 271, no. 1555 (2004): 2403-2410. 
[39] Owens, Jayanti. "Early childhood behavior problems and the gender gap in educational attainment in the United States." Sociology of education 89, no. 3 (2016): 236-258.

[40] Prevoo, Tyas, and Bas Ter Weel. "The effect of family disruption on childrens personality development: Evidence from British longitudinal data." De economist 163, no. 1 (2015): 61-93.

[41] Radloff, Lenore Sawyer. "The CES-D scale: A self-report depression scale for research in the general population." Applied psychological measurement 1, no. 3 (1977): 385401.

[42] Salisbury, Jane, Gareth Rees, and Stephen Gorard. "Accounting for the differential attainment of boys and girls at school." School Leadership \& Management 19, no. 4 (1999): 403-426.

[43] Segal, Carmit. "Misbehavior, education, and labor market outcomes." Journal of the European Economic Association 11, no. 4 (2013): 743-779.

[44] Slade, A., and Andrea H. Beller. "The role of family structure in the evolution of health from adolescence to young adulthood by gender." Unpublished Manuscript, University of Illinois at Urbana-Champaign, Department of Agricultural and Consumer Economics (2013).

[45] Trivers, Robert L., and Dan E. Willard. "Natural selection of parental ability to vary the sex ratio of offspring." Science 179, no. 4068 (1973): 90-92.

[46] OECD. "The ABC of gender equality in education: Aptitude, behaviour, confidence." (2015).

[47] U.S. Census Bureau. Educational Attainment in the United States: 2010. https://www.census.gov/data/tables/2010/demo/educational-attainment/cpsdetailed-tables.html (2016a).

[48] U.S. Census Bureau. Educational Attainment in the United States: 2015. http://www.census.gov/data/tables/time-series/demo/educational-attainment/cpshistorical-time-series.html (2016b).

[49] Woessmann, Ludger. "An international look at the single-parent family; family structure matters more for US students." Education Next 15, no. 2 (2015): 42-50. 


\section{A Data Appendix: Description of NLSY97 Sample}

NLSY97 is a representative longitudinal study with surveys from 1997 (round 1) to 20152016 (round 17). The cohort was born between 1980 and 1984, with respondents aged between 12 and 18 at the time of the first interview and between 30 and 36 at round 17. 8,984 individuals were initially interviewed in round 1 . Nearly 80 percent $(7,103)$ of the round 1 sample were interviewed in round 17. Consistent with Add Health sample, we uses subsamples of 1,486 non-Hispanic white women and 1,515 non-Hispanic white men who lived with their biological mother in round 1 survey. Table A3 shows summary statistics of important variables in both Add Health sample and NLSY97 sample. For most of the characteristics, these two samples are comparable.

\section{A.1 Adult Outcomes}

The round 17 interview collected an array of adult outcomes, including educational attainment, marriage, number of births, employment, income and depression.

- Educational Attainment: There are two survey questions on educational attainment. The first one is the highest grade completed as of the survey date, from 1st grade to 12 th grade, and from 1st year college to 8th year college or more. The second one is the highest degree received as of the survey date. In order to construct the educational attainment variable to be directly comparable to Add Health sample, the educational attainment is divided into 4 categories: "less than high school", "high school degree", "some college", and "college degree or more".17

As shown in Table A3, although the survey questions on educational attainment are different in two samples, the proportions of respondents with high school degree or more, and some college or more, are very similar in two samples. Though the proportion of respondents with college degree or more is higher in NLSY97 sample, for both female and male. In general, these two samples are comparable.

- Employment and Income: A dummy variable of currently employed is defined based on whether the respondent reports to receive any income from a job such as wages, salary, commissions, or tips. Personal income is measured by self-reported before-

\footnotetext{
${ }^{17}$ The educational attainment is defined to be "less than high school" if the respondent reports the highest degree to be "none". The educational attainment is defined to be "high school degree" if the respondent reports the highest degree to be GED or high school diploma, and the highest grade completed to be less or equal to 12th grade. The educational attainment is defined to be "some college" if the respondent reports the highest degree to be Associate/Junior college, or that the respondent reports the highest degree to be GED or high school diploma but the highest grade completed to be more or equal to 1st year college. The educational attainment is defined to be "college degree or more" if the respondent reports the highest degree to be Bachelor's degree, Master's degree, PhD or Professional degree (DDS, JD, MD).
} 
tax job income in 2014, in thousand of dollars. Job satisfaction for the primary current job is measured on a 5 point scale.

- Marriage and Children Ever Born: A dummy variable of ever married is defined based on the reported marriage history. The respondents were also asked about number of biological children born and residing in the household/born but not residing in the household as of the survey date. The children ever born variable is the sum of these two reported numbers.

- Depression: Respondents were asked how often during the past month they felt nervous, calm and peaceful, down or blue, happy, and depressed. Factor analysis indicated that a single factor is appropriate for these 5 items and was used to form a standardized depression index.

\section{A.2 Disadvantage: Father Absence}

During the round 1 survey, 93\% of the NLSY97 white non-Hispanic respondents were living with their biological mother. Of this group, $14 \%$ were living with a step-father or other father figure, and $21 \%$ were living with no father figure at all. As shown in Table A3, these two samples are comparable, while the proportion of respondents living with other father rather than biological father is higher in NLSY97 sample, for both female and male.

\section{A.3 Maternal Characteristics}

Maternal characteristics are included as control variables in most regressions. In the NLSY97 sample, there is only one survey question, the mother's highest grade completed, on biological mother's educational attainment. In order to be consistent with the categorical definitions in Add Health sample, the maternal educational attainment is defined to be "less than high school" if the highest grade completed is less or equal to 11th grade, "high school degree" if the highest grade completed is equal to 12th grade, "some college" if the highest grade completed is between 1st year college and 3rd year college, "college degree or more" if the highest grade completed is between 4th year college and 8th year college. As shown in Table A3, NLSY97 sample has smaller proportion of mother with high school degree, but larger proportion of mother with some college education. This is because the survey questions on educational attainment are different in two samples, making it hard to distinguish between "high school degree" and "some college" in the NLSY97 sample. However, the proportion of mother with college degree or more is very similar in these two samples. 


\section{B Appendix Tables}

Table A1: Sample Selection: Add Health Sample

\begin{tabular}{|c|c|c|c|c|c|}
\hline & $\begin{array}{c}1) \\
\text { Full } \\
\text { Sample }\end{array}$ & $\begin{array}{c}(2) \\
\text { With } \\
\text { Complete Data }\end{array}$ & $\begin{array}{c}(3) \\
\text { White Non-Hispanic } \\
\text { Subsample }\end{array}$ & $\begin{array}{c}(4) \\
\text { Living with } \\
\text { Biological Mother }\end{array}$ & $\begin{array}{c}(5) \\
\text { With Wave } \\
\text { IV Data }\end{array}$ \\
\hline Mother's Education: High School Degree & $\begin{array}{c}0.40 \\
(0.49)\end{array}$ & $\begin{array}{c}0.41 \\
(0.49)\end{array}$ & $\begin{array}{c}0.44 \\
(0.50)\end{array}$ & $\begin{array}{c}0.44 \\
(0.50)\end{array}$ & $\begin{array}{c}0.44 \\
(0.50)\end{array}$ \\
\hline Mother's Education: Some College & $\begin{array}{c}0.18 \\
(0.38)\end{array}$ & $\begin{array}{c}0.18 \\
(0.39)\end{array}$ & $\begin{array}{c}0.19 \\
(0.39)\end{array}$ & $\begin{array}{c}0.20 \\
(0.40)\end{array}$ & $\begin{array}{c}0.20 \\
(0.40)\end{array}$ \\
\hline Mother's Education: College Degree or More & $\begin{array}{c}0.24 \\
(0.42)\end{array}$ & $\begin{array}{c}0.23 \\
(0.42)\end{array}$ & $\begin{array}{c}0.25 \\
(0.43)\end{array}$ & $\begin{array}{c}0.26 \\
(0.44)\end{array}$ & $\begin{array}{c}0.26 \\
(0.44)\end{array}$ \\
\hline Young Mother & $\begin{array}{c}0.11 \\
(0.31)\end{array}$ & $\begin{array}{c}0.12 \\
(0.33)\end{array}$ & $\begin{array}{c}0.11 \\
(0.32)\end{array}$ & $\begin{array}{c}0.12 \\
(0.33)\end{array}$ & $\begin{array}{c}0.15 \\
(0.36)\end{array}$ \\
\hline Foreign Mother & $\begin{array}{c}0.15 \\
(0.35)\end{array}$ & $\begin{array}{c}0.12 \\
(0.33)\end{array}$ & $\begin{array}{c}0.04 \\
(0.19)\end{array}$ & $\begin{array}{c}0.04 \\
(0.19)\end{array}$ & $\begin{array}{c}0.03 \\
(0.18)\end{array}$ \\
\hline No Father & $\begin{array}{c}0.30 \\
(0.46)\end{array}$ & $\begin{array}{c}0.31 \\
(0.46)\end{array}$ & $\begin{array}{c}0.23 \\
(0.42)\end{array}$ & $\begin{array}{c}0.23 \\
(0.42)\end{array}$ & $\begin{array}{c}0.22 \\
(0.42)\end{array}$ \\
\hline Other Father & $\begin{array}{c}0.10 \\
(0.30)\end{array}$ & $\begin{array}{c}0.10 \\
(0.30)\end{array}$ & $\begin{array}{c}0.10 \\
(0.31)\end{array}$ & $\begin{array}{c}0.10 \\
(0.30)\end{array}$ & $\begin{array}{c}0.10 \\
(0.30)\end{array}$ \\
\hline Family Income at Baseline Survey & $\begin{array}{c}45.73 \\
(51.62)\end{array}$ & $\begin{array}{c}45.73 \\
(51.03)\end{array}$ & $\begin{array}{c}52.53 \\
(54.67)\end{array}$ & $\begin{array}{c}53.56 \\
(55.58)\end{array}$ & $\begin{array}{c}53.50 \\
(54.98)\end{array}$ \\
\hline Low Birth Weight & $\begin{array}{c}0.10 \\
(0.31)\end{array}$ & $\begin{array}{c}0.10 \\
(0.30)\end{array}$ & $\begin{array}{c}0.08 \\
(0.28)\end{array}$ & $\begin{array}{c}0.08 \\
(0.27)\end{array}$ & $\begin{array}{c}0.08 \\
(0.27)\end{array}$ \\
\hline Male & $\begin{array}{c}0.49 \\
(0.50)\end{array}$ & $\begin{array}{c}0.49 \\
(0.50)\end{array}$ & $\begin{array}{c}0.49 \\
(0.50)\end{array}$ & $\begin{array}{c}0.49 \\
(0.50)\end{array}$ & $\begin{array}{c}0.47 \\
(0.50)\end{array}$ \\
\hline Age at Baseline Survey & $\begin{array}{l}15.10 \\
(1.75)\end{array}$ & $\begin{array}{l}15.11 \\
(1.74)\end{array}$ & $\begin{array}{l}15.04 \\
(1.73)\end{array}$ & $\begin{array}{l}14.98 \\
(1.72)\end{array}$ & $\begin{array}{l}14.98 \\
(1.72)\end{array}$ \\
\hline Number of Observations & 20745 & 17320 & 10227 & 8916 & 7327 \\
\hline
\end{tabular}

Note: This table reports summary statistics for the Add Health sample. The first column is the full Add Health Wave I sample. The second column drops the observations without race/ethnicity data, or without Wave I sample weights. The third column further drops the observations that are not White Non-Hispanic. The fourth column keeps only those living with biological mother at Wave I, and with non-missing maternal characteristics. The fifth column keeps the observations that are still in the sample at Wave IV survey. The sample shown in column (5) is the main sample investigated in this paper. 
Table A2: Descriptive Statistics, Add Health Non-Hispanic White Sample

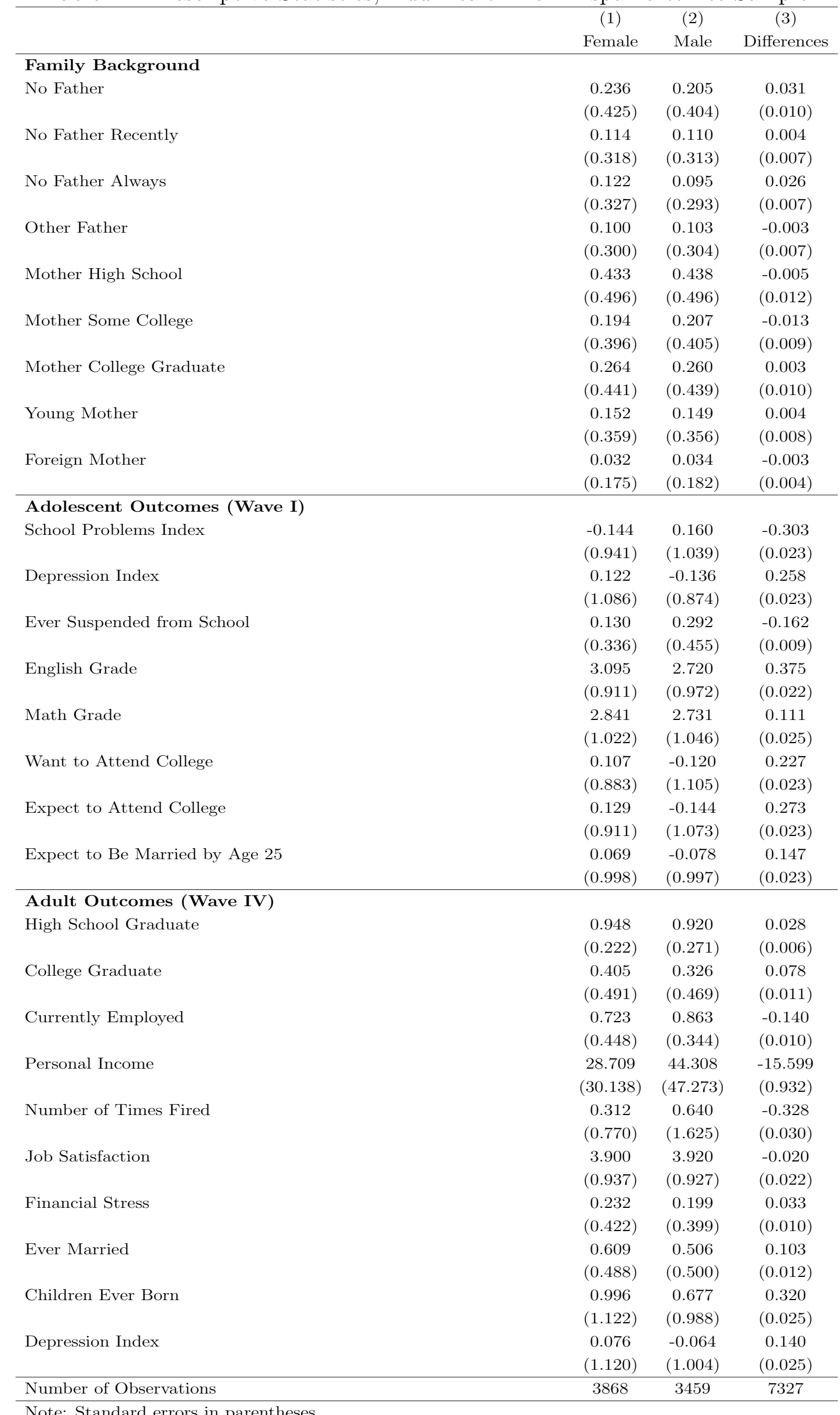


Table A3: Summary Statistics: Add Health and NLSY97 Non-Hispanic White Sample

\begin{tabular}{lcccc}
\hline & $(1)$ & $(2)$ & $(3)$ & $(4)$ \\
& Add Health Sample & \multicolumn{2}{c}{ NLSY97 Sample } \\
& Female & Male & Female & Male \\
\hline High School Graduation & 0.940 & 0.916 & 0.952 & 0.947 \\
At Least Some College & $(0.238)$ & $(0.278)$ & $(0.214)$ & $(0.225)$ \\
& 0.738 & 0.638 & 0.715 & 0.640 \\
College Graduation & $(0.440)$ & $(0.481)$ & $(0.452)$ & $(0.480)$ \\
Mother's Education: High School Degree & 0.388 & 0.320 & 0.443 & 0.358 \\
Mother's Education: Some College & $(0.487)$ & $(0.466)$ & $(0.497)$ & $(0.480)$ \\
Mother's Education: College Degree or More & 0.447 & 0.458 & 0.337 & 0.357 \\
No Father at Baseline Survey & $(0.497)$ & $(0.498)$ & $(0.473)$ & $(0.479)$ \\
& 0.194 & 0.197 & 0.288 & 0.256 \\
Other Father at Baseline Survey & $(0.396)$ & $(0.397)$ & $(0.453)$ & $(0.436)$ \\
& 0.235 & 0.248 & 0.249 & 0.273 \\
Family Income at Baseline Survey & $(0.424)$ & $(0.407)$ & $(0.415)$ & $(0.389)$ \\
& 0.098 & 0.099 & 0.145 & 0.138 \\
Age at Baseline Survey & $(0.297)$ & $(0.299)$ & $(0.352)$ & $(0.345)$ \\
Number of Observations & 43.117 & 43.403 & 47.979 & 46.134 \\
& $(47.923)$ & $(49.048)$ & $(47.815)$ & $(45.894)$ \\
Note: The Add & 14.727 & 14.938 & 14.289 & 14.295 \\
& $(1.751)$ & $(1.829)$ & $(1.491)$ & $(1.501)$ \\
& 3868 & 3459 & 1486 & 1515 \\
\hline
\end{tabular}

Note: The Add Health sample is weighted by Wave I sample weights. The NLSY97 sample is weighted by 1997 sample weights. The baseline survey for Add Health sample is in 19941995, while the baseline survey for NLSY97 sample is in 1997. The family income is measured in thousands of dollar. 
Table A4: Identification Tests, Add Health Non-Hispanic White Sample

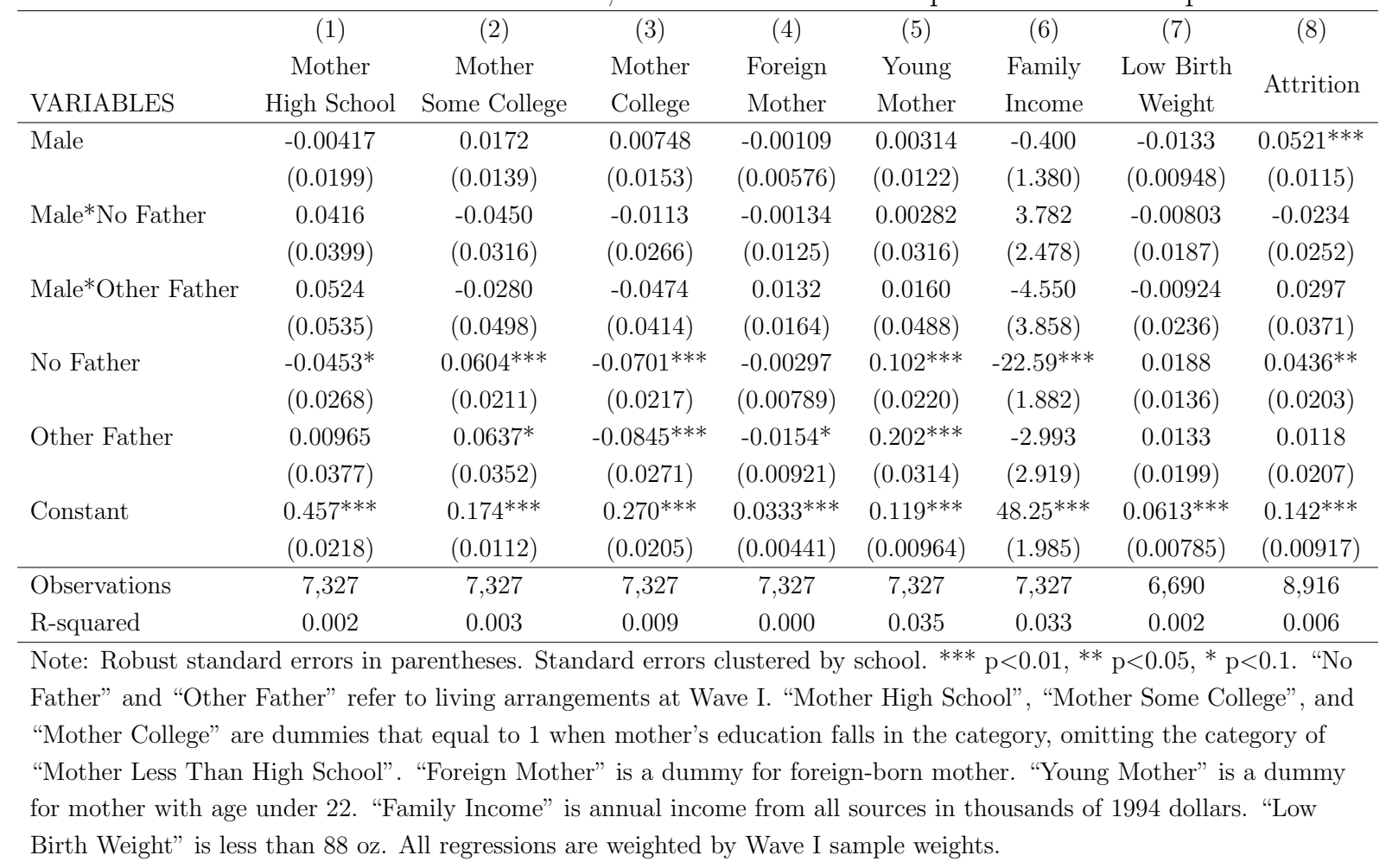




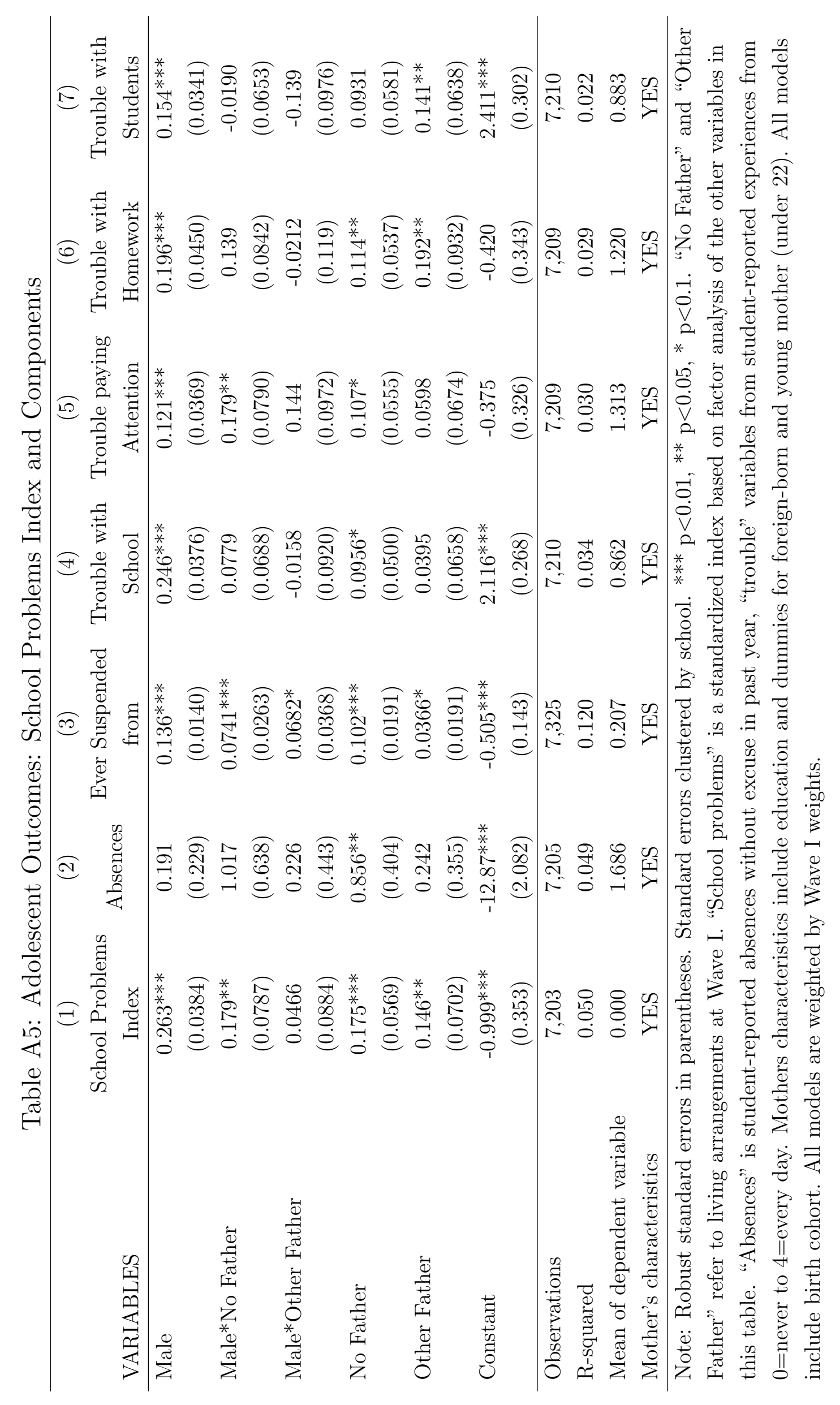


Table A6: Adolescent Outcomes: Depression Index and Components

\begin{tabular}{|c|c|c|c|c|c|c|c|}
\hline VARIABLES & $\begin{array}{l}(1) \\
\text { Depression } \\
\text { Index }\end{array}$ & $\begin{array}{c}(2) \\
\text { Hopeful } \\
\text { about Future }\end{array}$ & $\begin{array}{c}(3) \\
\text { Can't Shake } \\
\text { Blues }\end{array}$ & $\begin{array}{c}(4) \\
\text { Depressed }\end{array}$ & $\begin{array}{c}(5) \\
\text { Happy }\end{array}$ & $\begin{array}{c}(6) \\
\text { Lonely }\end{array}$ & $\begin{array}{l}(7) \\
\text { Sad }\end{array}$ \\
\hline Male & $\begin{array}{c}-0.240 * * * \\
(0.0295)\end{array}$ & $\begin{array}{c}0.0416 \\
(0.0292)\end{array}$ & $\begin{array}{c}-0.144^{* * *} \\
(0.0194)\end{array}$ & $\begin{array}{c}-0.163^{* * *} \\
(0.0223)\end{array}$ & $\begin{array}{l}-0.0193 \\
(0.0321)\end{array}$ & $\begin{array}{c}-0.133^{* * *} \\
(0.0219)\end{array}$ & $\begin{array}{c}-0.179 * * * \\
(0.0214)\end{array}$ \\
\hline Male*No Father & $\begin{array}{c}-0.000464 \\
(0.0663)\end{array}$ & $\begin{array}{l}-0.0576 \\
(0.0701)\end{array}$ & $\begin{array}{l}-0.0291 \\
(0.0529)\end{array}$ & $\begin{array}{c}-0.0965^{* *} \\
(0.0433)\end{array}$ & $\begin{array}{l}-0.0187 \\
(0.0672)\end{array}$ & $\begin{array}{c}0.0296 \\
(0.0458)\end{array}$ & $\begin{array}{l}0.00848 \\
(0.0427)\end{array}$ \\
\hline Male*Other Father & $\begin{array}{c}-0.205^{*} \\
(0.115)\end{array}$ & $\begin{array}{l}-0.0273 \\
(0.0997)\end{array}$ & $\begin{array}{c}-0.189 * * \\
(0.0795)\end{array}$ & $\begin{array}{c}-0.151^{* *} \\
(0.0699)\end{array}$ & $\begin{array}{l}-0.0132 \\
(0.0869)\end{array}$ & $\begin{array}{c}-0.00819 \\
(0.0699)\end{array}$ & $\begin{array}{l}-0.134^{*} \\
(0.0781)\end{array}$ \\
\hline No Father & $\begin{array}{c}0.184^{* * *} \\
(0.0489)\end{array}$ & $\begin{array}{l}-0.0304 \\
(0.0437)\end{array}$ & $\begin{array}{c}0.127^{* * *} \\
(0.0313)\end{array}$ & $\begin{array}{c}0.167 * * * \\
(0.0356)\end{array}$ & $\begin{array}{c}-0.0668^{*} \\
(0.0390)\end{array}$ & $\begin{array}{l}0.0571^{*} \\
(0.0299)\end{array}$ & $\begin{array}{c}0.0669 * * \\
(0.0335)\end{array}$ \\
\hline Other Father & $\begin{array}{c}0.272^{* * *} \\
(0.0969)\end{array}$ & $\begin{array}{l}-0.0169 \\
(0.0697)\end{array}$ & $\begin{array}{c}0.213^{* * *} \\
(0.0754)\end{array}$ & $\begin{array}{c}0.178^{* * *} \\
(0.0658)\end{array}$ & $\begin{array}{c}-0.0586 \\
(0.0636)\end{array}$ & $\begin{array}{c}0.104^{*} \\
(0.0531)\end{array}$ & $\begin{array}{l}0.139 * * \\
(0.0602)\end{array}$ \\
\hline Constant & $\begin{array}{c}-1.651^{* * *} \\
(0.260)\end{array}$ & $\begin{array}{c}0.915^{* * *} \\
(0.260)\end{array}$ & $\begin{array}{c}-0.616^{* * *} \\
(0.156)\end{array}$ & $\begin{array}{c}-0.595^{* * *} \\
(0.189)\end{array}$ & $\begin{array}{c}3.080^{* * *} \\
(0.261)\end{array}$ & $\begin{array}{c}-0.806^{* * *} \\
(0.157) \\
\end{array}$ & $\begin{array}{l}-0.181 \\
(0.167) \\
\end{array}$ \\
\hline Observations & 7,311 & 7,320 & 7,323 & 7,326 & 7,327 & 7,326 & 7,326 \\
\hline R-squared & 0.063 & 0.022 & 0.045 & 0.054 & 0.021 & 0.030 & 0.038 \\
\hline Mean of dependent variable & 0.000 & 1.870 & 0.364 & 0.488 & 2.183 & 0.423 & 0.537 \\
\hline Mother's characteristics & YES & YES & YES & YES & YES & YES & YES \\
\hline $\begin{array}{l}\text { Note: Robust standard erro } \\
\text { "No Father" and "Other Fa } \\
\text { scale (standardized) based } \\
\text { "How often have you felt th } \\
\text { Mothers characteristics incl } \\
\text { include birth cohort. All mo }\end{array}$ & $\begin{array}{l}\text { n parenth } \\
\text { " refer to } \\
9 \text { items, it } \\
\text { vay during } \\
\text { education }\end{array}$ & $\begin{array}{l}\text { es. Standard } \\
\text { living arranger } \\
\text { cluding the ot } \\
\text { the past week } \\
\text { and dummies }\end{array}$ & $\begin{array}{l}\text { ors clustere } \\
\text { nts at Wave } \\
\text { variables it } \\
\text { ranging fror } \\
\text { foreign-bor }\end{array}$ & $\begin{array}{l}\text { y school. } \\
\text { "Depres } \\
\text { his table. } \\
0=\text { never } \\
\text { and youn }\end{array}$ & $\begin{array}{l}{ }^{*} \mathrm{p}<0.01 \\
\text { Index" i } \\
\text { ch item } \\
\text { arely to } \\
\text { other ( } \mathrm{u}\end{array}$ & $\begin{array}{l}* * \mathrm{p}<0.0 \\
\text { the CES- } \\
\text { based on } \\
=\text { most } / \text { all } \\
\text { der } 22 \text { ). A }\end{array}$ & $\begin{array}{l}\mathrm{p}<0.1 \text {. } \\
\text { epression } \\
\text { ponses to } \\
\text { the time. } \\
\text { nodels }\end{array}$ \\
\hline
\end{tabular}


Table A7: Mechanisms: Adolescent Self-Reports about Relationship with Parents

\begin{tabular}{|c|c|c|c|c|}
\hline VARIABLES & $\begin{array}{c}(1) \\
\text { Parents Care } \\
\text { about Me }\end{array}$ & $\begin{array}{c}\text { (2) } \\
\text { Family } \\
\text { Has Fun }\end{array}$ & $\begin{array}{c}(3) \\
\text { Mother Warm } \\
\text { and Loving }\end{array}$ & $\begin{array}{c}\text { (4) } \\
\text { Satisfied with } \\
\text { Relationship with Mother }\end{array}$ \\
\hline \multirow[t]{2}{*}{ Male } & -0.00162 & 0.0527 & $0.0875^{* * *}$ & $0.156^{* * *}$ \\
\hline & $(0.0161)$ & $(0.0352)$ & $(0.0236)$ & $(0.0277)$ \\
\hline \multirow[t]{2}{*}{ Male*No Father } & 0.0102 & -0.0531 & 0.0378 & 0.0278 \\
\hline & $(0.0356)$ & $(0.0754)$ & $(0.0515)$ & $(0.0560)$ \\
\hline \multirow[t]{2}{*}{ Male*Other Father } & -0.0116 & 0.0123 & 0.104 & 0.0429 \\
\hline & $(0.0479)$ & $(0.0859)$ & $(0.0726)$ & $(0.0752)$ \\
\hline \multirow[t]{2}{*}{ No Father } & $-0.0666 * * *$ & $-0.148^{* * *}$ & $-0.147 * * *$ & $-0.126^{* * *}$ \\
\hline & $(0.0248)$ & $(0.0434)$ & $(0.0416)$ & $(0.0473)$ \\
\hline \multirow[t]{2}{*}{ Other Father } & -0.0429 & $-0.231^{* * *}$ & $-0.0999^{*}$ & -0.0176 \\
\hline & $(0.0373)$ & $(0.0734)$ & $(0.0600)$ & $(0.0646)$ \\
\hline \multirow[t]{2}{*}{ Constant } & $5.383^{* * *}$ & $6.132^{* * *}$ & $5.491 * * *$ & $6.303^{* * *}$ \\
\hline & $(0.106)$ & $(0.252)$ & $(0.176)$ & $(0.205)$ \\
\hline Observations & 7,306 & 7,301 & 7,319 & 7,318 \\
\hline R-squared & 0.013 & 0.038 & 0.026 & 0.036 \\
\hline Mean of dependent variable & 4.82 & 3.72 & 4.42 & 4.29 \\
\hline Mother's characteristics & YES & YES & YES & YES \\
\hline \multicolumn{5}{|c|}{$\begin{array}{l}\text { Note: Robust standard errors in parentheses. Standard errors clustered by school. }{ }^{* *} \mathrm{p}<0.01,{ }^{* *} \mathrm{p}<0.05 \text {, } \\
{ }^{*} \mathrm{p}<0.1 \text {. "No Father" and "Other Father" refer to living arrangements at Wave I. Dependent variables are } \\
\text { measured on a } 1-5 \text { scale (column } 1 \text { and } 2 \text { ) or a } 0-4 \text { scale (column } 3 \text { and } 4 \text { ) from "strongly disagree" to } \\
\text { "strongly agree". Mothers characteristics include education and dummies for foreign-born and young } \\
\text { mother (under 22). All models include birth cohort. All models are weighted by Wave I weights. }\end{array}$} \\
\hline
\end{tabular}




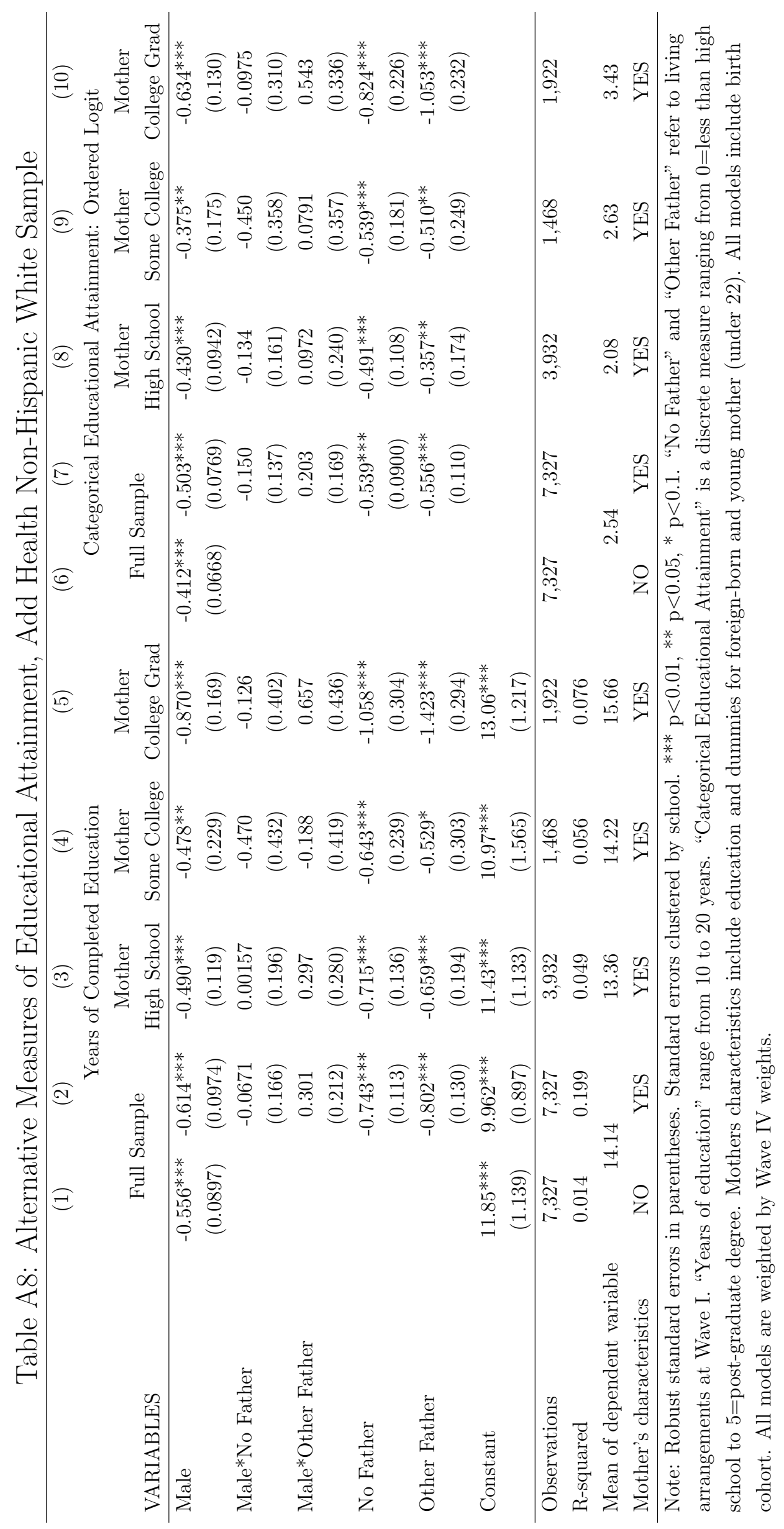




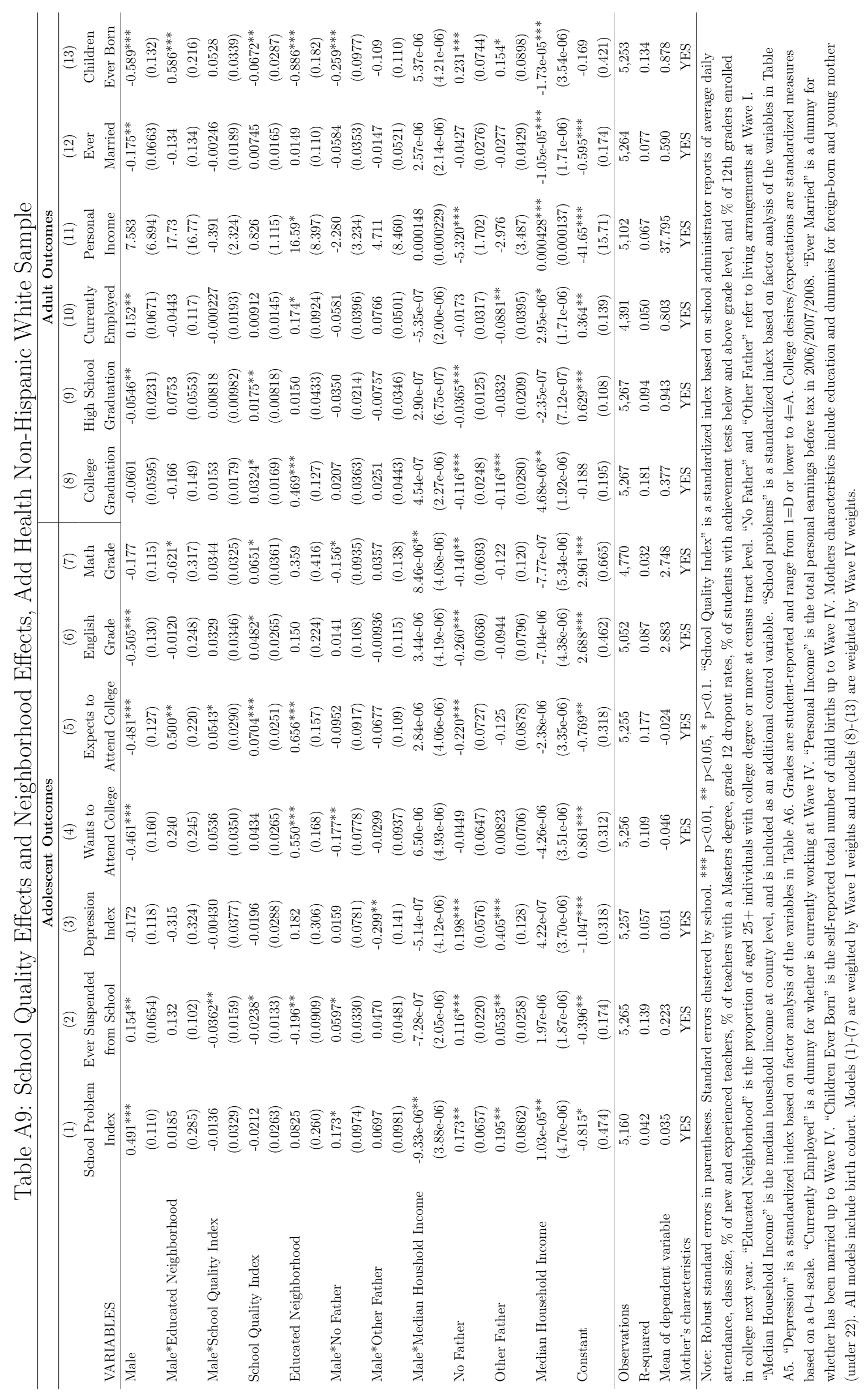




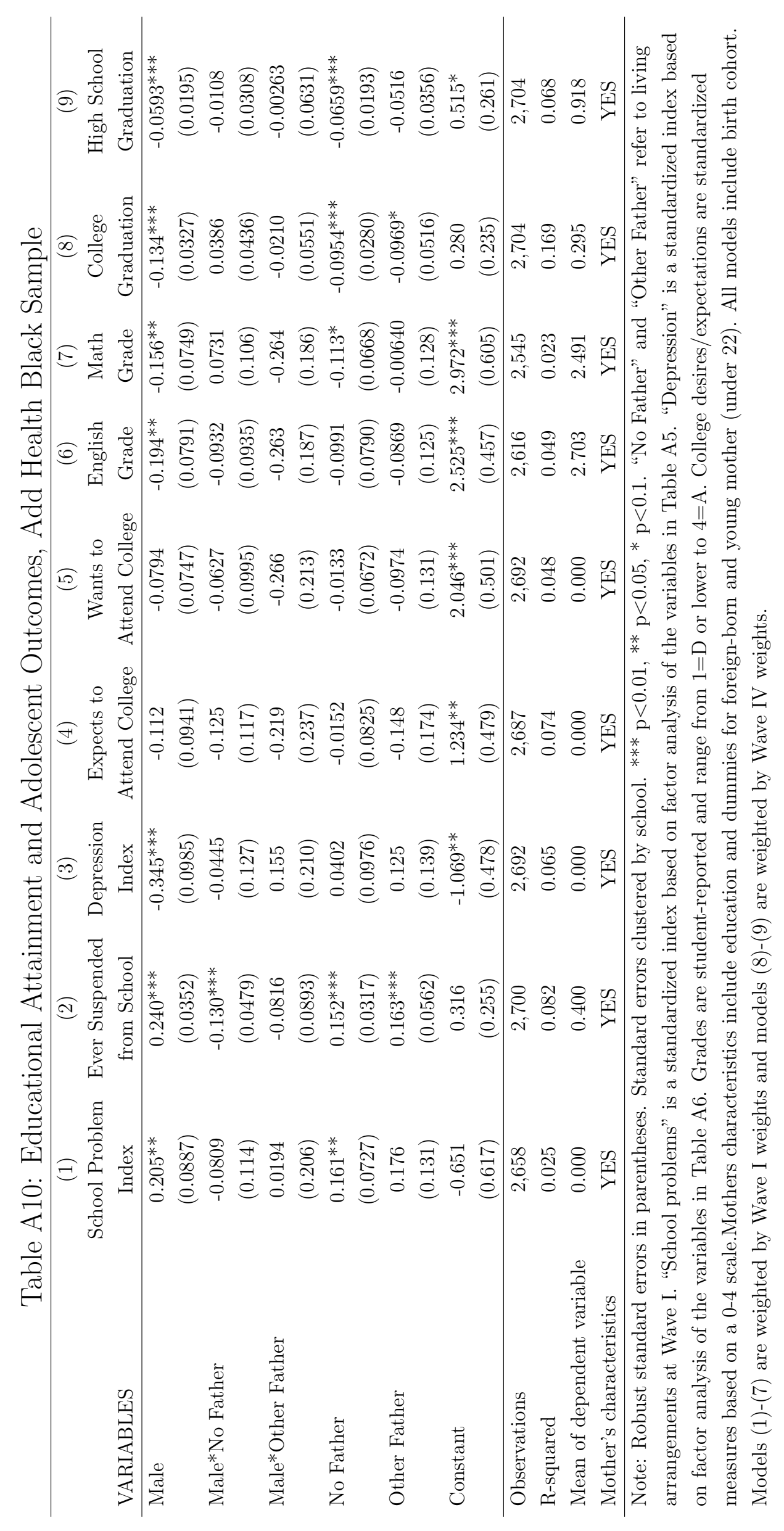




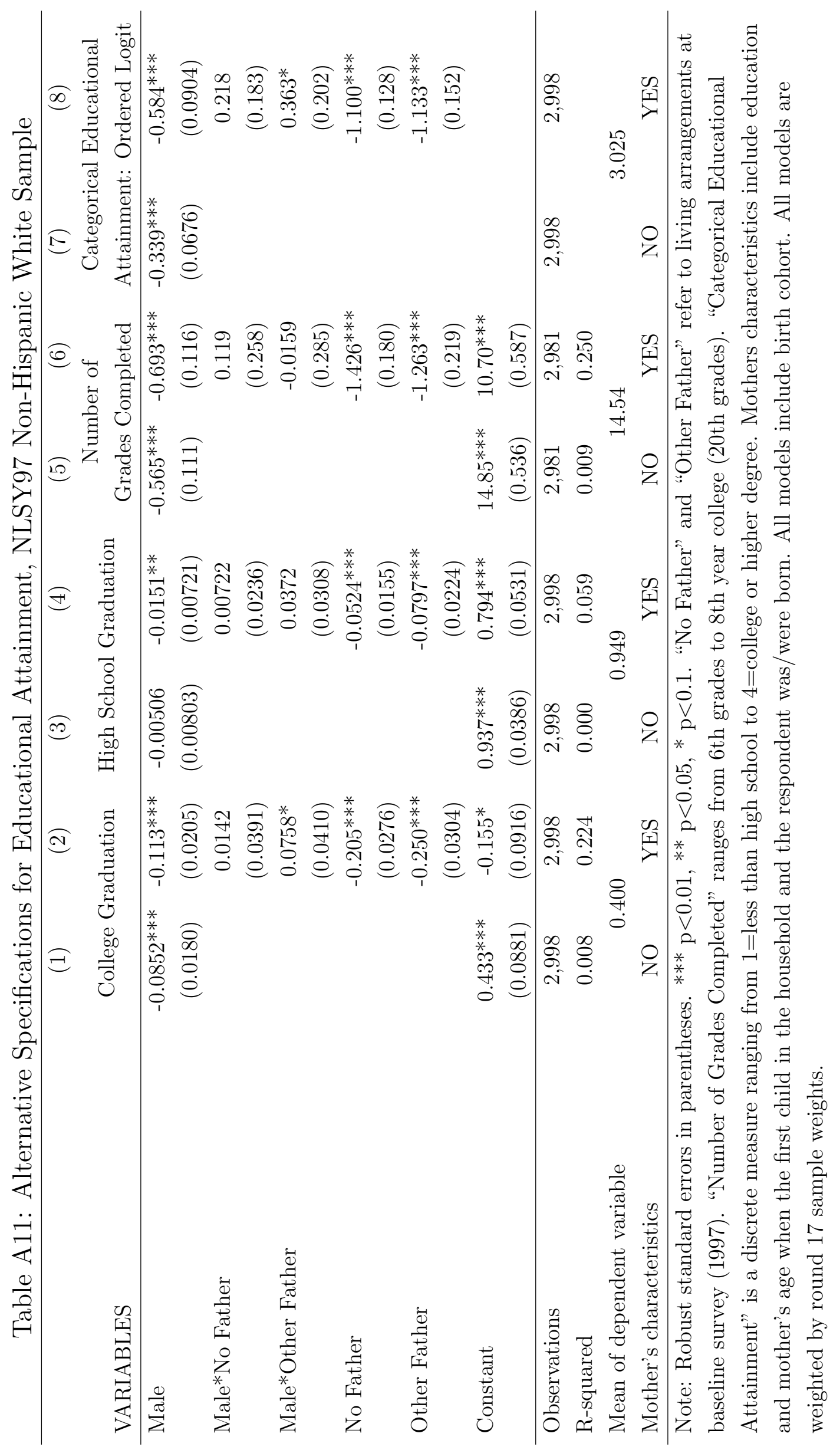

